\title{
Assimilation of Himawari-8 Clear Sky Radiance Data in JMA's Global and Mesoscale NWP Systems
}

\author{
Masahiro KAZUMORI \\ Numerical Prediction Division, Forecast Department, Japan Meteorological Agency, Tokyo, Japan
}

(Manuscript received 21 May 2017, in final form 31 January 2018)

\begin{abstract}
This article reports on the impacts of Himawari-8 Clear Sky Radiance (CSR) data assimilation in the global and mesoscale numerical weather prediction (NWP) systems of the Japan Meteorological Agency (JMA). Adoption of the Advanced Himawari Imager (AHI) on board JMA's Himawari-8 and -9 satellites has enhanced observational capabilities in terms of spectral, horizontal, and temporal resolution. Improvements brought by the switchover from the Multi-functional Transport Satellite-2 (MTSAT-2) to the new-generation Himawari-8 satellite include an upgrade to the horizontal resolution of CSR data from 64 to $32 \mathrm{~km}$ and an increase in the number of available water vapor bands from one to three. CSR products are obtained every hour and distributed to the NWP community. The improved horizontal and spectral resolution of Himawari-8 CSR data provides new information on horizontal water vapor distribution and vertical profiles in data assimilation.

In data assimilation experiments using JMA's global NWP system, the assimilation of Himawari-8's three water vapor bands significantly improved the tropospheric humidity field in analysis, especially in the lower troposphere, as compared to assimilation of the single MTSAT-2 water vapor channel. First-guess (FG) departure statistics for microwave humidity sounders indicated an improvement in the water vapor field, especially over Himawari-8 observation areas. Improved forecasting of tropospheric temperature, humidity, and wind fields for Himawari-8 observation areas was also seen.

In data assimilation experiments using JMA's mesoscale NWP system, a disastrous heavy precipitation event that took place in Japan's Kanto-Tohoku region in 2015 was investigated. A single water vapor band of Himawari-8 CSR corresponding to MTSAT-2 was assimilated, resulting in enhanced contrast of the water vapor field between moist and dry areas, as well as a realistic representation of moist air flows from the ocean in analysis. The changes also improved mesoscale model heavy precipitation forecasts.
\end{abstract}

Keywords Himawari-8; clear sky radiance; data assimilation; numerical weather prediction

\section{Introduction}

The new-generation Himawari-8 geostationary meteorological satellite was successfully launched on October 7, 2014 (Bessho et al. 2016). Clear Sky Radiance (CSR) data produced from Himawari-8 radiance observations have been distributed opera-

Corresponding author: Masahiro Kazumori, Numerical Prediction Division, Japan Meteorological Agency, 1-3-4, Ote-machi, Chiyoda-ku, Tokyo 100-8122, Japan

E-mail: kazumori@met.kishou.go.jp

J-stage Advance Published Date: 7 April 2018 tionally to the Numerical Weather Prediction (NWP) community since July 7, 2015. CSR data contain information on tropospheric humidity under clear-sky conditions. In this study, the impacts of Himawari-8 CSR data assimilation in the global and mesoscale NWP systems of the Japan Meteorological Agency (JMA) were investigated.

CSR data from geostationary satellites are operationally assimilated by several NWP centers (Munro et al. 2004; Köpken et al. 2004; Szyndel et al. 2005; Su et al. 2003; Ishibashi 2008; Stengel et al. 2009; Zou et al. 2011; Qin et al. 2013; Zou et al. 2015; 
Laurence et al. 2016) into their global and regional NWP systems. As the continuity of geostationary observation by space agency satellite programs is ensured, the CSR data are viewed as highly important in current global humidity observation for NWP. Geostationary satellite observation data provide detailed and continuous information on atmospheric water vapor, cloud, and surface conditions for lowand mid-latitude areas. Data in the infrared channel that measures radiance at about 6.7 micrometers, which detects radiation emitted by water vapor have been used for a long time to monitor upper- and mid-tropospheric water vapor distribution in realtime weather analysis and forecasting. CSR data from these bands are produced for assimilation into NWP systems. The current generational transition of geostationary satellites is providing considerable improvements in temporal, spatial, and spectral resolution, which are expected to bring substantial changes in the utilization of such data.

Meanwhile, microwave radiometers on board polar-orbiting satellites [e.g., Advanced Microwave Scanning Radiometer 2 (AMSR2), Global Precipitation Measurement (GPM) Microwave Imager (GMI), and Special Sensor Microwave Imager/Sounder (SSMIS)] have provided humidity data for operational environmental monitoring for a long time, and the information has been assimilated by operational NWP centers (Sato et al. 2004; Bauer et al. 2006; Kazumori 2014; Kazumori and Egawa 2014; Kazumori 2016). CSR data from geostationary satellites provide near-real-time water vapor information in clear-sky conditions, thereby yielding significant advantages in terms of continuous data utilization for global and regional NWP systems. The Geostationary Operational Environmental Satellites (GOES)-13 and 15 , Meteosat- 8 and -10 , and Himawari-8 are currently the primary operational geostationary meteorological satellites of the global observing system.

The Advanced Himawari Imager (AHI) has 16 bands for radiance observations, unlike the 5 channels of the previous Multi-functional Transport Satellite (MTSAT)-2. Himawari-8's three water vapor absorption bands $(6.2,6.9$, and 7.3 micrometers, referred to as bands 8,9 , and 10 , respectively) have the potential to capture water vapor vertical profile information. The spatial resolution of the original pixel configuration is enhanced to $2 \mathrm{~km}$ in Himawari- 8 data, as compared to $4 \mathrm{~km}$ for MTSAT-2. The observation band and horizontal resolution differences are summarized in Table 1. The horizontal resolution of the Himawari-8 CSR data used in this study was
Table 1. Wavelength and horizontal resolution of Himawari-8 observation bands and MTSAT-2 (1R) channels. Water vapor channels are shown in bold.

\begin{tabular}{|c|c|c|c|c|}
\hline \multirow{2}{*}{$\begin{array}{l}\text { Wave } \\
\text { length } \\
\text { (micro } \\
\text { meter) }\end{array}$} & \multicolumn{2}{|c|}{ Himawari-8 } & \multicolumn{2}{|c|}{$\begin{array}{l}\text { MTSAT-2, } \\
\text { MTSAT-1R }\end{array}$} \\
\hline & $\begin{array}{l}\text { Band } \\
\text { number }\end{array}$ & $\begin{array}{l}\text { Horizontal } \\
\text { resolution } \\
(\mathrm{km})\end{array}$ & $\begin{array}{l}\text { Channel } \\
\text { name }\end{array}$ & $\begin{array}{l}\text { Horizontal } \\
\text { resolution } \\
(\mathrm{km})\end{array}$ \\
\hline 0.47 & 1 & 1 & & \\
\hline 0.51 & 2 & 1 & & \\
\hline 0.64 & 3 & 0.5 & VIS & 1 \\
\hline 0.86 & 4 & 1 & & \\
\hline 1.6 & 5 & 2 & & \\
\hline 2.3 & 6 & 2 & & \\
\hline 3.9 & 7 & 2 & IR4 & 4 \\
\hline 6.2 & 8 & 2 & IR3 & 4 \\
\hline 6.9 & 9 & 2 & & \\
\hline 7.3 & 10 & 2 & & \\
\hline 8.6 & 11 & 2 & & \\
\hline 9.6 & 12 & 2 & & \\
\hline 10.4 & 13 & 2 & IR1 & 4 \\
\hline 11.2 & 14 & 2 & & \\
\hline 12.4 & 15 & 2 & IR2 & 4 \\
\hline 13.3 & 16 & 2 & & \\
\hline
\end{tabular}

$32 \mathrm{~km}$ while that of the MTSAT-2 CSR data was $64 \mathrm{~km}$. This improved resolution provides new information on the fine horizontal structure of water vapor fields. Temporal resolution is dramatically improved in Himawari-8, full-disk observation data with the original pixels are provided every $10 \mathrm{~min}$ (as compared to MTSAT-2 observation at 30-min intervals), and the Japan area is observed every 2.5 min. At JMA's Meteorological Satellite Center, the current Himawari-8 CSR data are produced for the full-disk area every hour, as with MTSAT-2 CSR data. Although both types of CSR data are produced on an hourly basis, the full-disk data have a 10-min time range for Himawari-8 CSR, as compared to a 30-min time range for MTSAT-2 CSR data. Accordingly, more temporally appropriate first-guess (FG) fields can be used in Himawari-8 CSR data assimilation. CSR data are distributed to NWP centers in Binary Universal Form for the Representation of meteorological data (BUFR) in real time. The assimilation of Himawari-8 CSR data instead of MTSAT-2 CSR data is expected to bring further amelioration in analysis and forecast fields.

Several operational NWP centers around the world have started using Himawari-8 CSR data in their global data assimilation systems. These centers are the 
following.

(1) The European Centre for Medium-Range Weather Forecasts (ECMWF), which started assimilating three water vapor bands of Himawari-8 CSR data in January 2016. The assimilation has facilitated the extraction of dynamical information via the tracing effect (see Section 4.1) in the ECMWF 4D-Var system (Peubey and McNally 2009). The improved spatial resolution of Himawari- 8 CSR data has also enabled the use of enhanced cloud and aerosol masking. ECMWF test results show that Himawari-8 CSR assimilation has reduced forecast errors more than MTSAT-2 CSR assimilation (Laurence et al. 2016).

(2) The Met Office, which also started assimilating Himawari-8 CSR data in November 2016. The assimilation has improved the analysis of temperature and humidity (Met Office 2016).

(3) The Météo-France, which started using Himawari-8 CSR data in its global NWP system in December 2015 (Météo-France 2016).

(4) The National Centers for Environmental Prediction (NCEP), which have investigated the impacts of raw Himawari-8 AHI radiance data in their global data assimilation system. Clear-sky ocean-only radiances were assimilated. The impacts have reduced the analysis and forecast errors in uppertropospheric humidity relative to ECMWF analysis (Ma et al. 2017).

In preparation for the geostationary satellite switchover from MTSAT-2 to Himawari-8 in the western Pacific region, the impacts of Himawari-8 CSR data assimilation were investigated using JMA's NWP systems to clarify the benefits of related operational use. On the basis of the above discussion, this paper is organized as follows. Section 2 describes JMA's data assimilation systems and Himawari-8 CSR data. Section 3 presents the data pre-processing developed for quality control (QC) and a related cloud identification method. Section 4 details the results of assimilation experiments conducted with JMA's global and mesoscale NWP systems. Section 5 gives a summary and outlines future prospects.

\section{Data assimilation systems and Himawari-8 Clear Sky Radiance data}

\subsection{Data assimilation systems}

In this study, JMA's operational global DA (data assimilation) and mesoscale DA systems were used for Himawari-8 CSR data assimilation experiments. CSR data from the previous MTSAT-2 and MTSAT1R satellites have been assimilated into the global
DA system since 2008 (Ishibashi 2008) and into the mesoscale DA system since 2010 (Kazumori 2014). CSR data from other geostationary satellites (i.e., GOES-13 and 15, Meteosat-8 and 10) are also assimilated into the global DA system. During the period of the DA experiments, Meteosat-7 was operational over the Indian Ocean. MTSAT-2 and Himawari-8 CSR data cover the domain of the mesoscale DA system while other geostationary satellites do not include the mesoscale model domain.

JMA's global NWP system consists of a global spectral model and a four-dimensional variational DA system (Japan Meteorological Agency 2013). JMA's global spectral model (JMA GSM) runs eight times a day from $00,06,12$, and 18 UTC initial conditions. It has a horizontal resolution of approximately $20 \mathrm{~km}$ and 100 layers with a $0.01 \mathrm{hPa}$ top height. JMA's global DA system uses an incremental four-dimensional variational (4D-Var) assimilation approach (Courtier et al. 1994) for producing initial conditions for the JMA GSM. The control variables in 4D-Var are relative vorticity, unbalanced divergence, unbalanced temperature, surface pressure, as well as a logarithm of specific humidity in spectral space. The horizontal resolution of the outer model is approximately 20 $\mathrm{km}$ while that of the inner model used to calculate the increment is approximately $55 \mathrm{~km}$. Both models have 100 vertical layers plus one surface layer in analysis, whose cycles are performed with a six-hour assimilation window. The JMA GSM produces 11-day forecasts from 12 UTC initial conditions and 84-hour forecasts from 00, 06, and 18 UTC initial conditions. The types of assimilated observations are (1) conventional data [e.g., radiosonde (used to measure pressure, temperature, humidity, and wind vectors), wind-profiler, aircraft (wind, temperature), surface synoptic observations (pressure), ship (pressure), buoy (pressure), and atmospheric motion vectors], (2) satellite data [e.g., from the Advanced Microwave Sounding Unit-A (AMSU-A), Microwave Humidity Sounder (MHS), Sondeur Atmosphérique du Profil d'Humidité Intertropicale par Radiométrie (SAPHIR), Atmospheric Infrared Sounder (AIRS), Infrared Atmospheric Sounding Interferometer (IASI), AMSR2, GMI, and SSMIS], CSR data from geostationary satellites (MTSAT-2, GOES-13 and 15, and Meteosat-8 and 10), zenith total delay from the ground-based Global Navigation Satellite System (GNSS), bending angles from GNSS radio-occultation data, surface wind from the Advanced Scatterometer (ASCAT), and (3) pseudo data (typhoon bogus data consisting of wind and surface pressure data 
empirically estimated from geostationary and polarorbiting satellite imagery in data-sparse areas in the presence of tropical cyclones (TC) in the North-West Pacific).

JMA's mesoscale NWP system consists of a mesoscale model (MSM) and a 4D-Var DA system (Japan Meteorological Agency 2013). A nonhydrostatic model (i.e., JMA NHM, Saito et al. 2006) was used as the mesoscale model. The MSM produces 39-hour forecasts every three hours with lateral boundary conditions given by the JMA GSM. The control variables in the 4D-Var are two horizontal wind components, potential temperature, surface pressure, and pseudo relative humidity (i.e., specific humidity divided by the saturated specific humidity of the FG). The horizontal resolution of the JMA MSM is $5 \mathrm{~km}$, and the model top is at approximately $22 \mathrm{~km}$. The DA system is a non-hydrostatic modelbased 4D-Var (the JMA Nonhydrostatic ModelBased Variational Analysis Data Assimilation scheme, JNoVA, Honda et al. 2005). The horizontal resolution of the outer model is $5 \mathrm{~km}$ and that of the inner model is $15 \mathrm{~km}$. The main purpose of the mesoscale NWP system is to produce accurate precipitation forecasts for extreme meteorological phenomena in and around Japan. Conventional, satellite, and groundbased remote sensing data are assimilated in the MSM domain. In addition to the operational data set, hourly precipitation data from Japan's ground-based weather radar network and precipitation data from microwave imagers (AMSR2, GMI, SSMIS) over the ocean are assimilated (Koizumi et al. 2005; Sato et al. 2004). Relative humidity profile data from groundbased radars and a space-based DPR (dual-frequency precipitation radar) are also assimilated (Ikuta and Honda 2011; Ikuta 2016). The above JMA NWP systems are described in JMA (2013).

The RTTOV fast radiative transfer model (Saunders et al. 1999) is used as a satellite radiance observation operator in JMA's global and mesoscale DA systems. RTTOV is developed and maintained by the European Organisation for the Exploitation of Meteorological Satellites (EUMETSAT) and widely adopted by NWP centers for radiance DA. In this study, RTTOV version 10 (Saunders et al. 2012), which is the version used in JMA's operational system, was adopted.

\subsection{Himawari-8 Clear Sky Radiance data}

JMA's Meteorological Satellite Center produced CSR data from MTSAT satellites (Uesawa 2009) every hour until Himawari-8 entered operation. These data were produced from radiance observed via the 6.7-micrometer water vapor absorption band (IR3) on MTSAT-2 and MTSAT-1R, and they are assimilated into global and regional models at various NWP centers (Ishibashi 2008; Kazumori 2014; Lupu and McNally 2011; Verner and Deblonde 2012; Tingwell et al. 2015). In JMA's operational global NWP system, the MTSAT-2 CSR data were thinned for selection every two hours. The thinning was conservatively determined to prevent possible temporal correlation of MTSAT CSR data observation errors when the data were introduced operationally. However, no negative impacts were observed when the hourly data were assimilated into JMA's mesoscale DA system (Kazumori 2014). The increased horizontal resolution of Himawari-8 CSR data was advantageous in helping to clarify the details of water vapor structure. Accordingly, hourly CSR data from Himawari-8 were assimilated for both the global and mesoscale DA systems in this study.

MTSAT-2 and Himawari-8 CSR data are produced in $16 \times 16$-pixel arrays known as segments. The horizontal scale of MTSAT-2 pixels is $4 \mathrm{~km}$ and that of Himawari-8 pixels is $2 \mathrm{~km}$, making the horizontal resolutions of MTSAT-2 CSR and Himawari-8 CSR, 64 and $32 \mathrm{~km}$, respectively. The improved horizontal resolution of Himawari-8 increases the amount of available CSR data. Information on the fine structure of tropospheric water vapor fields was obtained in DA.

In Himawari-8 CSR data production (Imai and Uesawa 2016), the cloudy pixels affected to a lesser extent by the low-level clouds are regarded as clear pixels with a threshold for atmospheric transmittance at the cloud top. This increases the amount of available pixel data in the segment and results in greater availability of CSR data compared to MTSAT-2 CSR data, which were produced from regular pixels only (i.e., those with no cloud at any altitude). This difference represents a major improvement of Himawari-8 CSR data from the previous MTSAT-2 CSR data (Uesawa 2009; Imai and Uesawa 2016). The accuracy of CSR data (i.e., the precision of clear-pixel selection) depends on the accuracy of the atmospheric profiles used in transmittance calculation and retrieval errors of estimated cloud top height. Thus, the development of a cloud screening method for use in pre-processing was necessary for Himawari-8 CSR DA; otherwise, the assimilation of cloud-contaminated CSR data could cause spurious analysis increments of water vapor and temperature. For clear-pixel data in one segment, the CSR is calculated as the average brightness temperature of clear-pixel data for each 
band. The standard deviation of clear-pixel data, ratio of clear pixels in the segment, latitude, longitude, and zenith angles of the segment center, as well as land/ sea flag information are also produced. The averaging of clear-pixel radiance in the segment produces smooth data. Current Himawari-8 CSR data have a horizontally smooth resolution of approximately 32 $\mathrm{km}$ while that of the inner model for data assimilation is approximately $55 \mathrm{~km}$ for the global DA system and $15 \mathrm{~km}$ for the mesoscale DA system. Accordingly, the current Himawari-8 CSR resolution is suitable for global DA and inappropriate for mesoscale DA. The use of high-resolution CSR products for mesoscale DA is a target for future research.

The three water vapor bands of Himawari-8 have different levels of sensitivity to individual water vapor layers in the atmosphere. Figure 1 illustrates the weighting functions of Himawari-8 infrared bands and MTSAT-2 infrared channels. The atmospheric profiles used in the calculation of these functions are from the US standard atmosphere. Himawari- 8 bands 9 and 10 exhibit sensitivity to lower-tropospheric water vapor. For accurate extraction of atmospheric water vapor information in DA, the surface emissivity and surface temperature used in radiative transfer calculation should be estimated accurately enough to be reliable. For the land surface, the surface emissivity and land surface temperature data from JMA's global model are not fully evaluated in surface-sensitive radiance assimilation. Accordingly, Himawari- 8 band 9 and 10 CSR data for areas over land were not used in this study.

Identification of cloudy pixels in CSR data production is based on thresholds of transmittance calculated under clear-sky conditions. Optically thick cloud pixels can be identified easily with the threshold technique for areas over the open oceans, but erroneous identification may occur for areas over snow-covered land and sea ice areas. Hence, the CSR data for areas over sea ice are not used in assimilation.

A cloud-clearing approach (Smith et al. 2004; Wang et al. 2015) has also been proposed as another clearscreening method for infrared radiance. This technique is applicable to hyperspectral sounder (e.g., AIRS) data, and partially cloudy field of view (FOV) data are cloud-cleared with information from a high-resolution infrared imager [e.g., MODIS (MODerate resolution Imaging Spectroradiometer)] on the same satellite. The cloud-cleared approach is advantageous in that the data are produced without additional atmospheric profiles from outputs of NWP forecast models. However, collocated observation data from two instruments (a high-resolution imager for clear-pixel identification and an infrared sounding instrument data for assimilation) are required. It should also be noted that the scene uniformity of the atmosphere, surface, and cloud influence the accuracy of cloud screening for CSR data and cloud-cleared radiance data. The standard deviations of observed radiances in the segment are used to remove non-uniform Himawari-8 CSR scene data as outlined in Section 3.
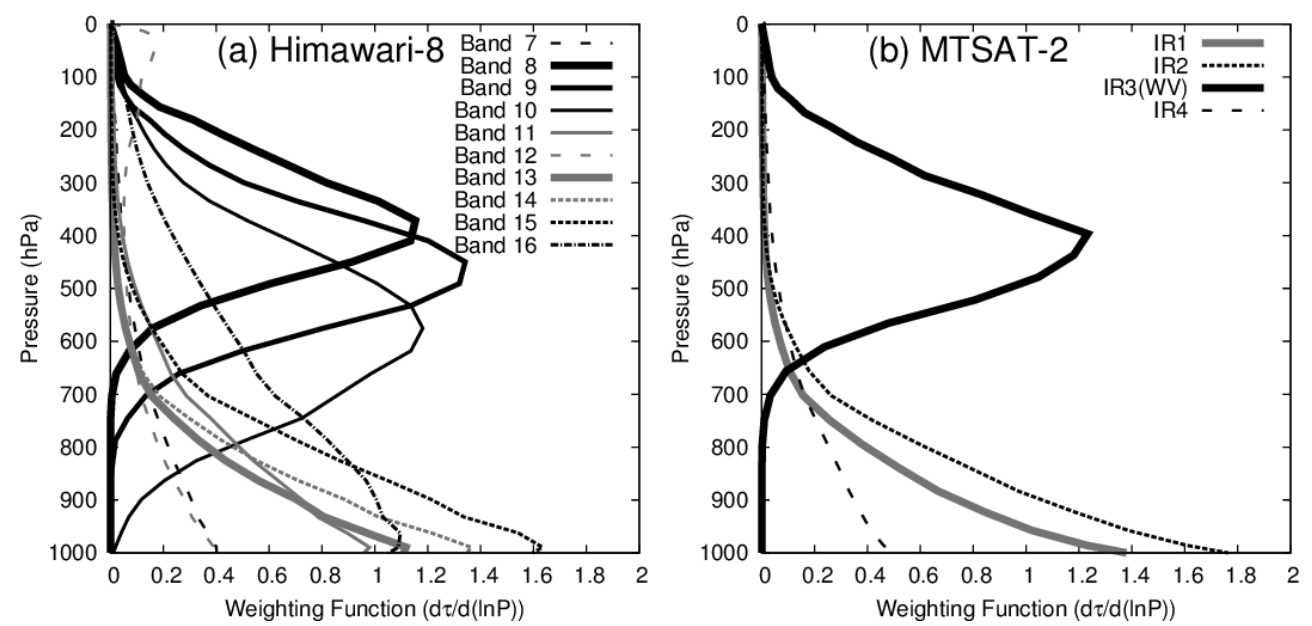

Fig. 1. Weighting functions of (a) Himawari-8 and (b) MTSAT-2 observation bands. Corresponding bands for Himawari- 8 and MTSAT-2 are shown with the same line type. The atmospheric profile used in radiative transfer calculation is from the US standard atmosphere. 


\section{Quality control in data pre-processing}

Cloud screening is a crucial part of pre-processing in clear sky radiance DA. Assimilation of cloudcontaminated CSR data would cause spurious humidity and temperature increments, creating potentially negative impacts on the accuracy of analysis and forecasts. Such data should be comprehensively removed to enable the extraction of pure tropospheric humidity information in the analysis.

In CSR data production (Uesawa 2009; Imai and Uesawa 2016), the cloud screening and clear-scene identification methods are used. These approaches are applied for each pixel data in the segment, and their performance determines the quality of CSR data.

For MTSAT-2 CSR data (Uesawa 2009), a key part of clear-scene identification was a threshold defined with window channel (10.8-micrometer) radiance data. The threshold was constructed using the maximum 10.8-micrometer band radiance value observed in the last 20 days. It incorporates surface temperature information for a clear-sky condition and can be used as an index for clear-pixel selection. As window channel information is used, the low-level cloud scenes were removed in MTSAT-2 CSR data.

For Himawari-8 CSR data (Imai and Uesawa 2016), the clear pixels are identified with computed atmospheric transmittances for each band. These transmittances for bands 7-16 are calculated using a radiative transfer model with thresholds defined for each band. Therefore, even if low-level clouds are present, some water vapor bands (e.g., those of band 8) can be taken as clear-scene data due to their negligible influence from such a cloud. However, the validity of the atmospheric transmittance threshold should be checked in pre-processing for DA and FG departure (observation minus first guess) statistics.

In pre-processing, Himawari-8 CSR data (three water vapor bands) with clear-pixel ratios exceeding $90 \%$ are selected. The band 13 (10.4-micrometer) clear-pixel ratio is also used for additional cloud checking. For the QC, the CSR data for Himawari-8 water vapor bands 8,9 , and 10 should have band-13 clear-pixel ratios exceeding 55\%, 60\%, and $65 \%$, respectively. These thresholds were determined empirically from the standard deviation and biases of the FG departures of the three water vapor bands. A stricter threshold is applied for the lower-humiditysensitive band. This QC effectively removes the lowlevel-cloud-contaminated CSR data.

After this cloud screening in the pre-processing step, the quality of Himawari-8 CSR data in terms of FG departure statistics was similar to that of MTSAT-2 CSR data. Figure 2 shows a time-series representation of the FG departure bias and standard deviation in Himawari-8 and MTSAT-2 CSR data. Figure 3 illustrates a comparison of the mean FG departure distributions of the two data types. The standard deviations of FG departure for the three water vapor bands were approximately $1 \mathrm{~K}$, as shown (a) Himawari-8 CSR

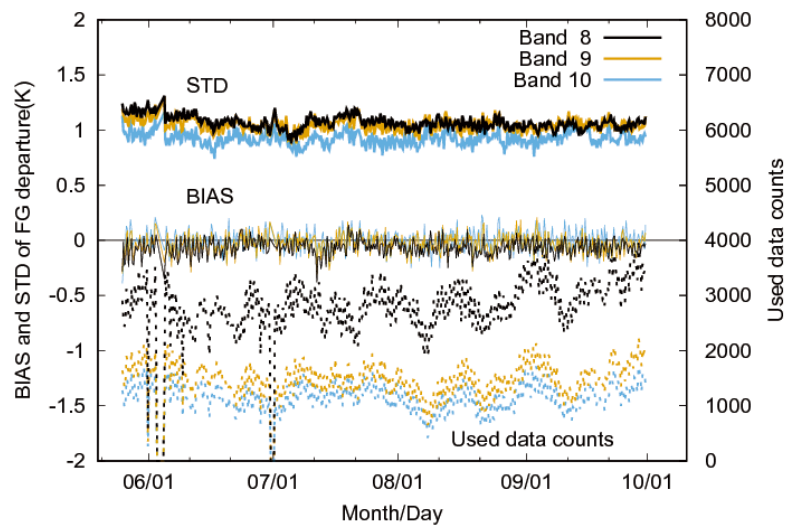

(b) MTSAT-2 CSR

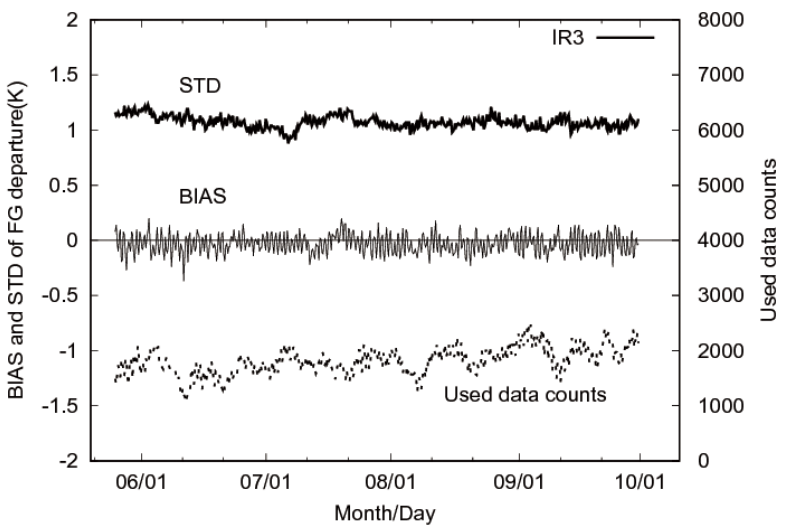

Fig. 2. Time-series representations of bias-corrected FG departure statistics (bias (BIAS), standard deviation (STD), and used data counts) for CSR data in the global data assimilation experiments. Thin solid lines indicate biases while thick solid lines indicate standard deviations. Dotted lines indicate assimilated data counts for the axes on the right. (a) The black represents band 8, orange is band 9, and light blue band 10 for Himawari-8 CSR, (b) MTSAT-2 CSR. 
in Fig. 2. The thresholds for gross error checking of FG departure were set as $3 \mathrm{~K}$ while the observation errors in the assimilation were conservatively set as $1.5 \mathrm{~K}$. These Himawari- 8 CSR settings are the same as those used for MTSAT-2 CSR. Although CSR data are assumed to be uncorrelated in the DA systems, the adjacent water vapor bands of Himawari-8 may exhibit some correlation. Therefore, the slightly increased observation error setting is considered as a reasonable starting point for the initial impact study. Pre-processing is commonly applied in JMA's global and mesoscale DA systems.

\section{Data assimilation experiments}

Assimilation experiments with Himawari-8 CSR data were conducted using the global and mesoscale DA systems. In the global system, the CSR data from Himawari-8 bands 8,9 , and 10 were assimilated. Band 8 data were assimilated in allsurface conditions. However, only oceanic data for band 9 and 10 were assimilated to prevent land surface signal contamination in dry atmospheric conditions. For the mesoscale DA system, singleband (band 8) Himawari-8 CSR data were assimilated to allow equivalent comparison of impacts between Himawari-8 CSR and MTSAT-2 CSR. The data were thinned horizontally with thinning distances of $220 \mathrm{~km}$ for the global system and $45 \mathrm{~km}$ for the mesoscale system as per MTSAT-2 CSR in the operational systems. Hourly Himawari-8 CSR data were assimilated into both NWP systems. It should be noted that MTSAT-2 CSR data in the global system were used on a two-hourly basis, as with the JMA operational configuration described
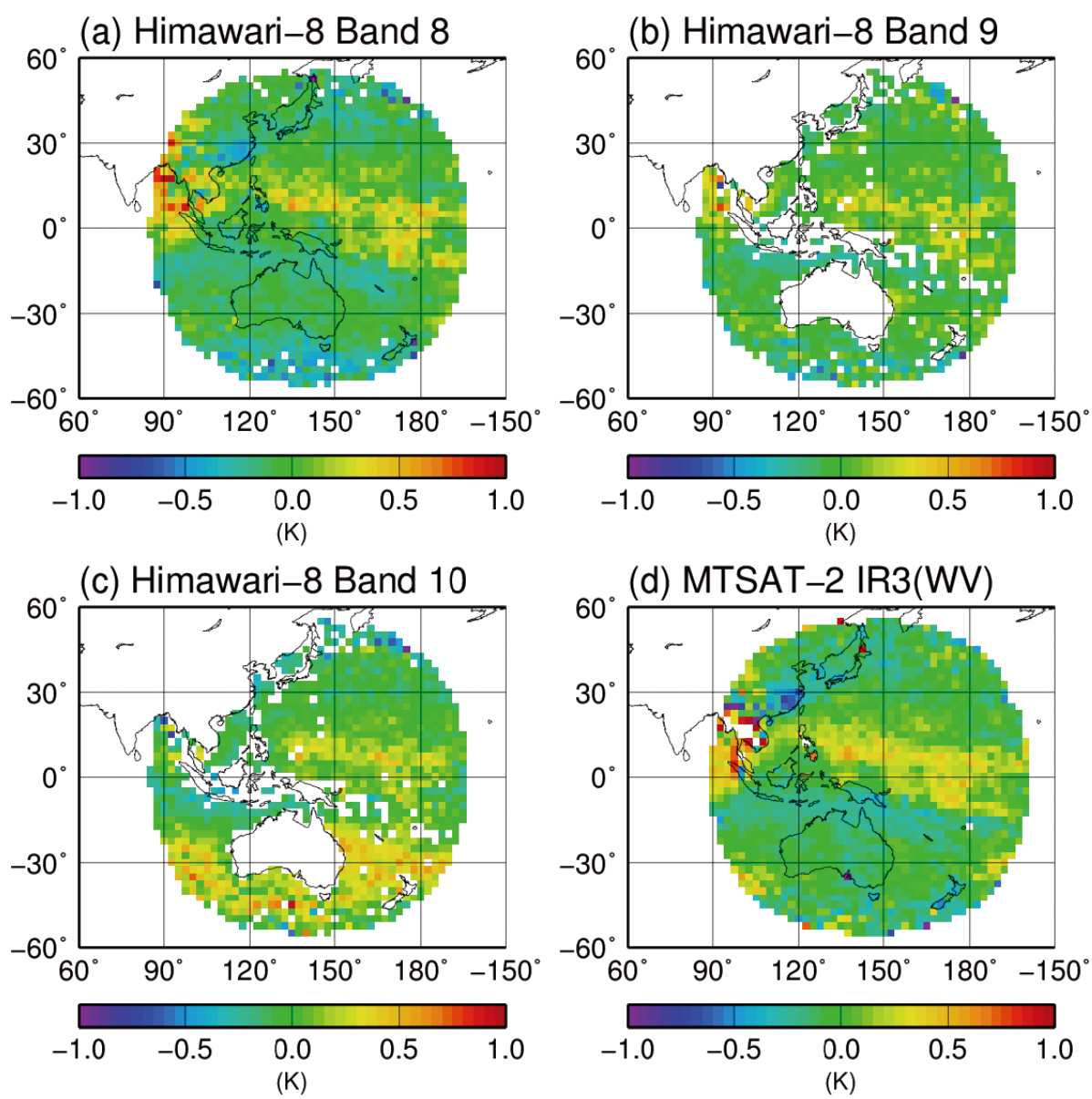

Fig. 3. Comparison of mean FG departure for Himawari-8 CSR (a) band 8, (b) band 9, (c) band 10, and (d) MTSAT-2 CSR in the global data assimilation system. Data are quality-controlled and bias-corrected. The period is from May 26 to September 30, 2015. 
in the previous section. Impacts from Himawari-8 CSR data enhancement (i.e., temporal, spectral, and horizontal resolution) were evaluated in the global DA experiments, and the enhanced horizontal resolution was evaluated in the mesoscale DA experiments.

For radiance DA into JMA's global NWP system, variational bias correction (VarBC, Dee 2004; Sato 2007) is applied. Biases are estimated using a polynomial function with several predictors. The predictors for CSR data in JMA's global DA system are the simulated brightness temperature of the assimilated band, satellite zenith angle, and global offset. The coefficients are estimated during minimization of the 4D-Var cost function in analysis and updated every six hours. In the mesoscale DA system, the estimated coefficients for CSR data in the global system were used (Kazumori 2014). The mesoscale NWP system has its own DA cycle and its lateral boundary conditions were taken from JMA's operational global model forecast. The use of common lateral boundary conditions in the experiments helped to highlight the clear impacts of Himawari-8 CSR DA in the mesoscale NWP system.

In the case of the replacement of satellite data used in the operational systems, the updated NWP systems should exhibit equivalent or superior performance in terms of analysis and forecasts quality. For verification, FG fitting to the existing observations in the NWP systems is examined (e.g., radiances from AMSU-A and MHS, temperature, humidity, and wind from radiosonde observations) for both the global and mesoscale systems. These are indispensable metrics to demonstrate that the new observation data are consistent with those of current observation and do not cause deterioration in analysis or forecasting. Improved forecast skill for high- and low-pressure systems from global NWP is also key feature to weather forecasting in and around Japan. The accuracy of precipitation forecasting from the mesoscale NWP system is another crucial element as the main target of this system is precipitation forecasting for high-impact weather events. These metrics were investigated in the DA experiments.

\subsection{Impact study with JMA's global NWP system}

The experimental configuration of Himawari-8 CSR DA with JMA's global NWP system is shown in Table 2. The period of the experiment was from May 26 to September 30, 2015. Although this was partially before the official release of Himawari-8 CSR data (July 7, 2015), the qualitative stability of the data for the entire duration of the experiment was
Table 2. Used CSR data in the data assimilation experiment with the global system.

\begin{tabular}{cc}
\hline $\begin{array}{c}\text { Experiment } \\
\text { Name }\end{array}$ & Used CSR data \\
\hline TEST & Himawari-8 CSR (Band 8, 9, 10) \\
CNTL & MTSAT-2 CSR (IR3) \\
BASE & No CSR data in the western Pacific region \\
\hline
\end{tabular}

confirmed. More Himawari-8 CSR data than MTSAT2 CSR were available in the system. CNTL was in line with the JMA's operational global NWP system as of 2015, and MTSAT-2 CSR data were used. Figure 2 shows FG departure statistics for CSR data as determined from the global DA experiments. The results indicate that the quality of CSR data was stable and that bias correction was effective. The number of data used depends on meteorological conditions in the Himawari-8 observation area. Such a stable quality of data is necessary for use in operational NWP systems.

Figure 3 displays the mean FG departure of the assimilated CSR data. The corresponding channels of Himawari-8 band 8 (Fig. 3a) and MTSAT-2 IR3 (Fig. 3d) showed a similar horizontal bias pattern with a water vapor field bias for the upper troposphere in the FG. However, the characteristics of bias distribution in the FG departure of Himawari-8 band-10 (Fig. 3c) data differ from those of band 8 , with the bias pattern for the lower-tropospheric water vapor field in the FG over the ocean contrasting those from the upper levels. These results suggest that band-10 CSR DA affected the lower-tropospheric water vapor field in analysis, especially over ocean areas.

Figure 4 shows the impact of CSR DA on water vapor fields in analysis. The results indicate that the assimilation of Himawari-8 CSR data significantly increased humidity in middle levels (from 850 to $500 \mathrm{hPa}$ ) for mid- and low latitudes, as compared to MTSAT-2 CSR data. The amounts of water vapor were decreased in the analysis at levels below 850 $\mathrm{hPa}$. The analysis increment in the water vapor field brought by Himawari- 8 CSR data was larger than increments from other observations on humidity.

To determine the related impacts on analysis and FG fields, the FG departures of the observation data commonly used in the experiments were examined. Figure 5 illustrates the differences in the root mean square (RMS) of the FG departure in MHS for TEST and CNTL from baseline experiment (BASE). The RMS reduction for MHS Channel 5 was greater in TEST than in CNTL. As MHS Channel 5 is more sensitive to lower-level water vapor than other MHS 

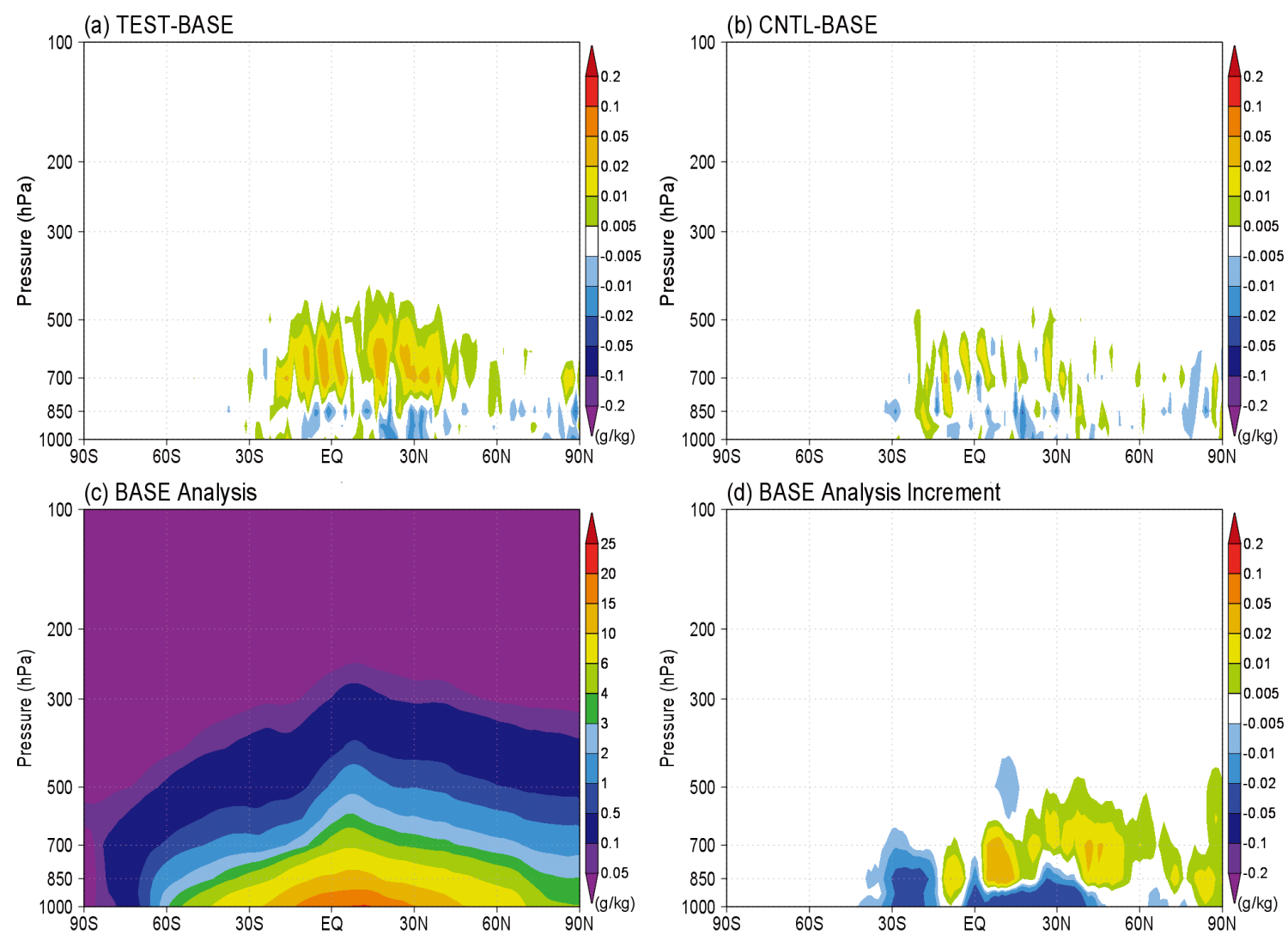

Fig. 4. Zonal average monthly mean difference in the specific humidity field for the analysis, mean specific humidity field, and analysis increment for July 2015. (a) mean difference in the specific humidity field between TEST and BASE analysis, (b) as per (a), but for the difference between CNTL and BASE analysis. (c) mean specific humidity field of BASE analysis, (d) mean analysis increment for specific humidity of BASE. The units are $\mathrm{g} \mathrm{kg}^{-1}$.

channels, the results indicate an improvement in the lower-level water vapor field for FG in the Himawari-8 observation area for TEST. Meanwhile, the singlechannel assimilation of MTSAT-2 CSR data provided similar enhancements in the middle- and upper-level water vapor field in CNTL. Minor impacts of MTSAT-2 CSR DA for the low-level water vapor field were observed and greater amounts of assimilated CSR data for parts of mainland China in TEST brought improvements in the upper tropospheric water vapor field in FG for inland areas of the country.

Changes in standard deviations of FG departures for other current observations indicated consistent enhancement of FG fields. Figure 6 shows normalized changes in these standard deviations for (a) microwave sounder radiance data, (b) infrared sounder radiance data (IASI), (c) radiosonde temperature, and (d) radiosonde relative humidity. These results show substantial amelioration in middle- and uppertropospheric temperature and humidity for FG fields. The improvements in TEST were greater than those in CNTL.

Figure 7 shows biases of FG departure in radiosonde relative humidity observation for the tropics (latitudes from $20^{\circ} \mathrm{S}$ to $20^{\circ} \mathrm{N}$ ). The FG field exhibits clear dry biases in the middle level (850-400 $\mathrm{hPa}$ ) and wet biases for lower (below $850 \mathrm{hPa}$ ) and upper (above $400 \mathrm{hPa}$ ) levels. Bias reductions were made by the assimilation of Himawari- 8 CSR data while the impacts of MTSAT-2 CSR assimilation were minor. Himawari-8 CSR DA produced higher humidity values for the middle troposphere and lower values for the lower troposphere, thereby reducing forecast model biases. These changes resulted from the humidity sensitivity of Himawari-8 CSR data.

Changes in the water vapor field in the analysis 
(a) TEST MHS $\mathrm{CH} 3$

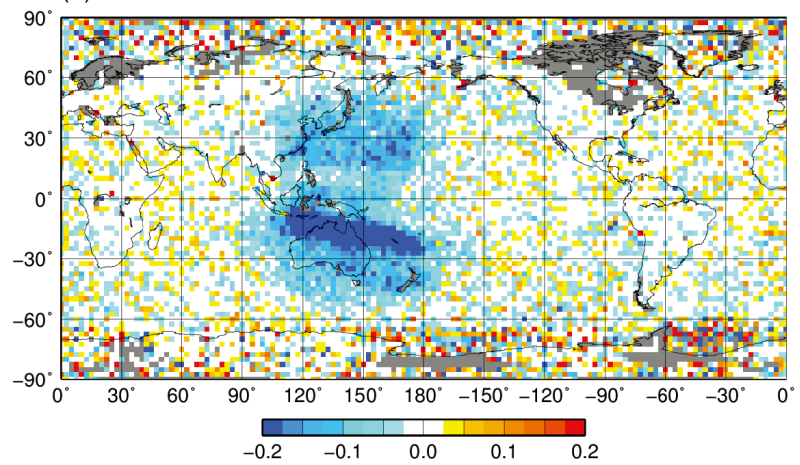

(c) TEST MHS CH4

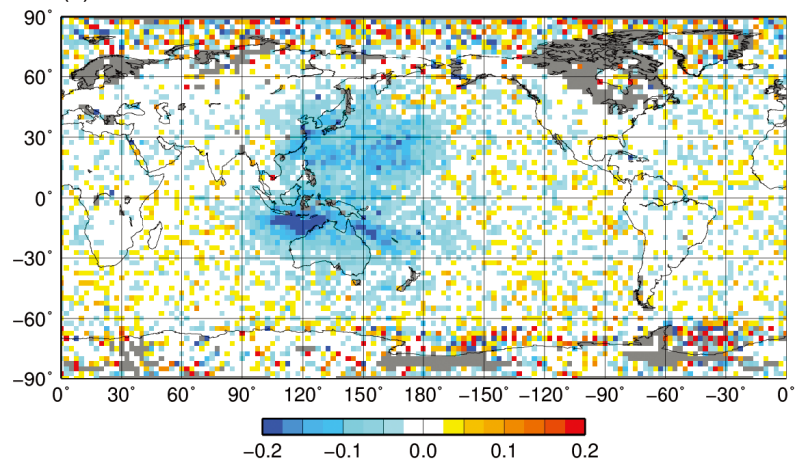

(e) TEST MHS CH5

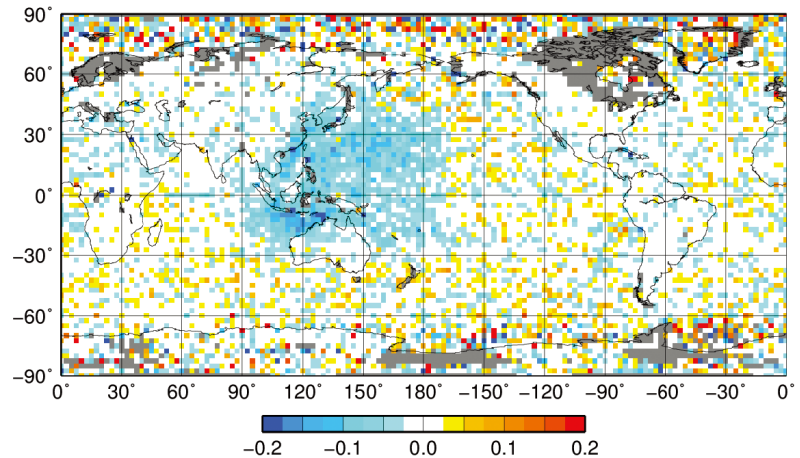

(b) CNTL MHS CH3

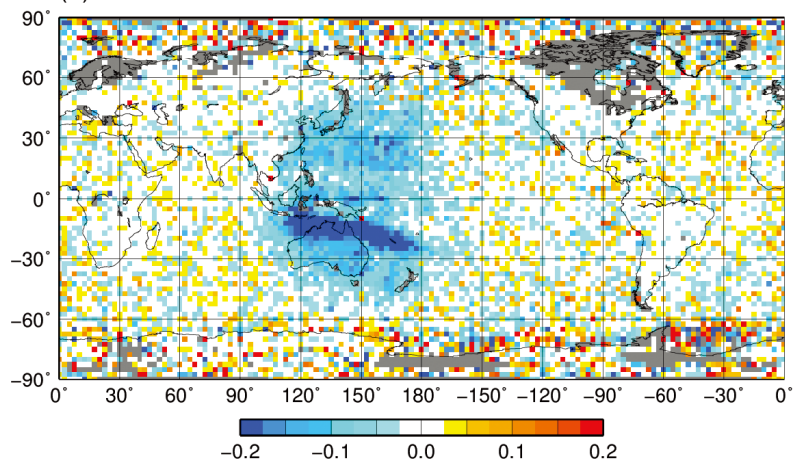

(d) CNTL MHS CH4

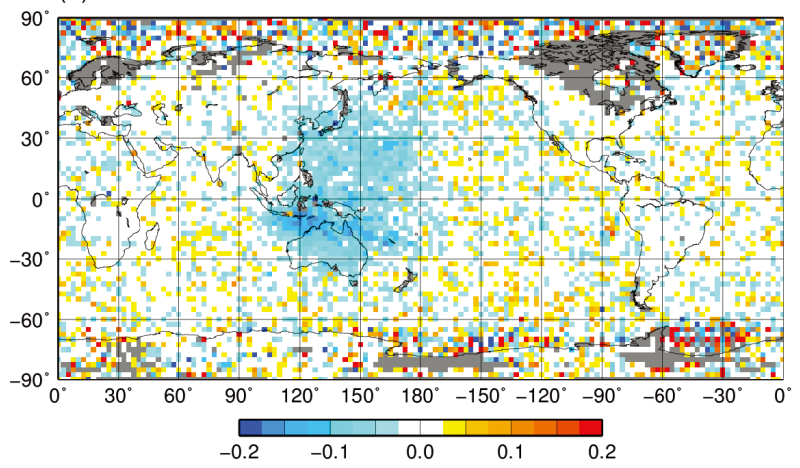

(f) CNTL MHS CH5

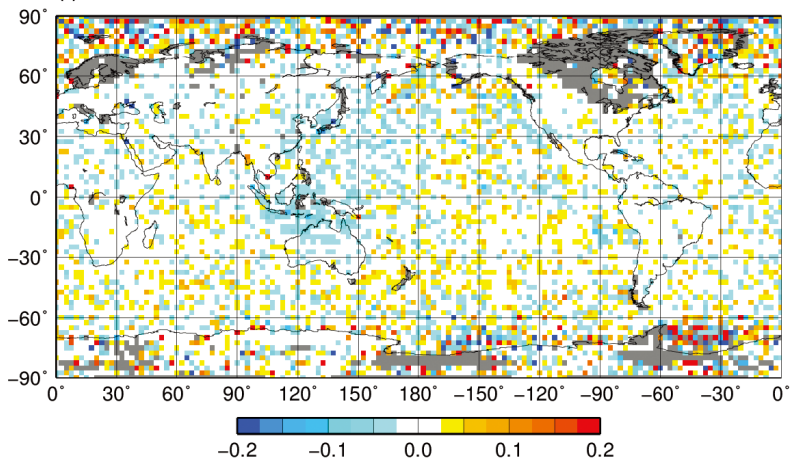

Fig. 5. Distribution of reduced RMS in MHS (Microwave Humidity Sounder) FG departure with colors indicating normalized changes. (a) MHS Channel 3 for TEST, (b) MHS Channel 3 for CNTL, (c) and (d) the same for MHS Channel 4, and (e) and (f) the same for MHS Channel 5. The MHS data used for the statistics are those assimilated in the experiments. Blue areas indicate RMS reduction, representing water vapor field improvement in the channel's sensitive layer. The period is from May 26 to September 30, 2015.

(Fig. 4) were observed in the 48-hour forecast range, but disappeared in longer-range forecasts (not shown). Conventional standard forecast scores (e.g., RMS errors of $500 \mathrm{hPa}$ geopotential height, $850 \mathrm{hPa}$ and $250 \mathrm{hPa}$ wind, sea level pressure field against initial fields) were neutral, and no statistically significant differences for either the Northern Hemisphere (latitudes from $20^{\circ} \mathrm{N}$ to $90^{\circ} \mathrm{N}$ ) or the
Southern Hemisphere (latitudes from $90^{\circ} \mathrm{S}$ to $20^{\circ} \mathrm{S}$ ) were observed. Although the impacts on forecast scores were largely neutral on a hemispheric scale, the regional impacts were observed in forecast wind fields. Figure 8 presents the differences in RMS errors from BASE for the zonal component of wind forecasts based on the verification against radiosonde observations. The statistics were calculated for Japan 

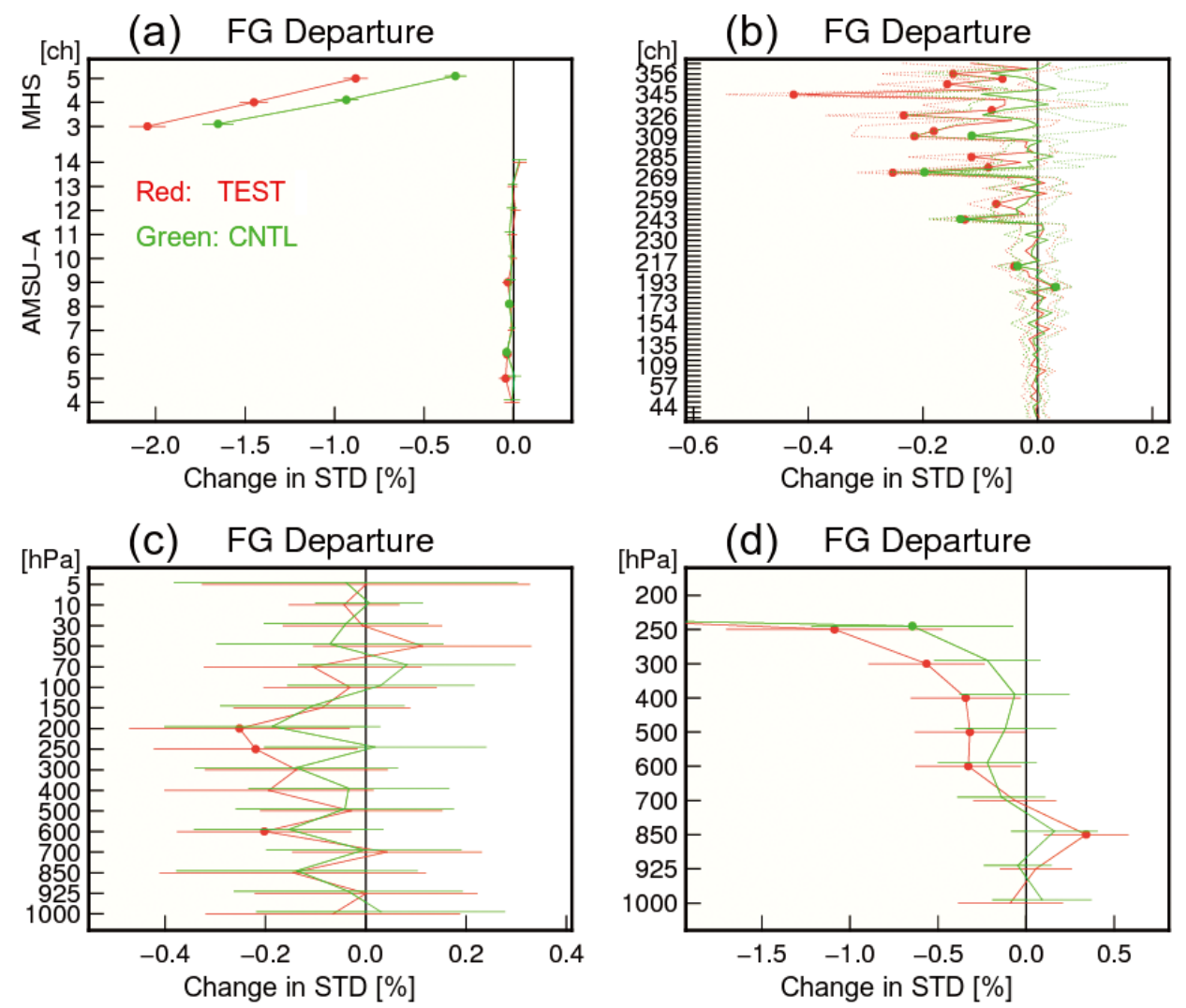

Fig. 6. Normalized change in standard deviation (STD) of FG departures from BASE for observations: (a) microwave temperature sounder (AMSU-A), humidity sounder (MHS), (b) IASI, (c) radiosonde temperature, and (d) radiosonde relative humidity. Red: TEST (Himawari-8 CSR usage), green: CNTL (MTSAT-2 CSR usage). The period is from May 26 to September 30, 2015. Error bars [dotted lines in (b)] and dots indicate $95 \%$ confidence intervals.

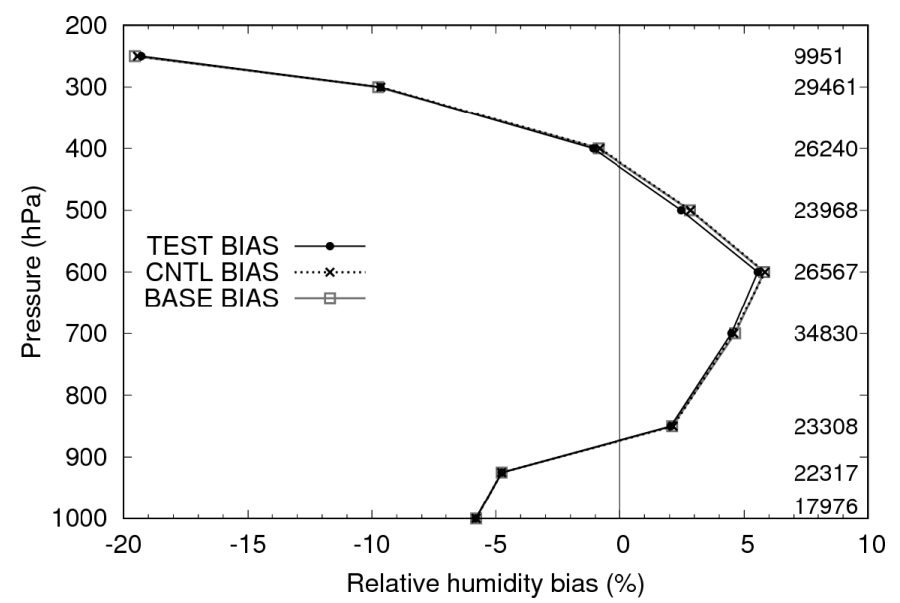

Fig. 7. Biases of relative humidity FG departure for radiosonde observations in the Tropics. The solid, dashed, and gray lines denote biases of FG departure in TEST, CNTL, and BASE, respectively. The period is from May 26 to September 30,2015 for latitudes $20^{\circ} \mathrm{S}$ to $20^{\circ} \mathrm{N}$. The data counts used in the statistics are shown on the right side of the panel. 
(a) TEST

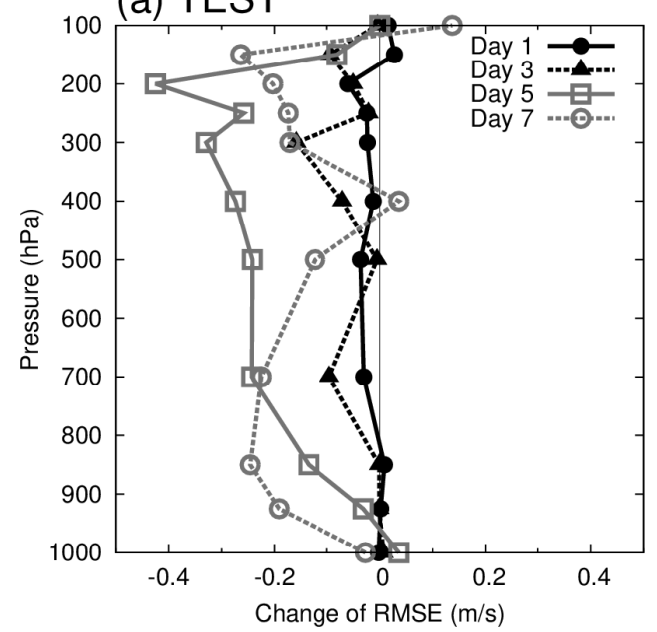

(b) CNTL

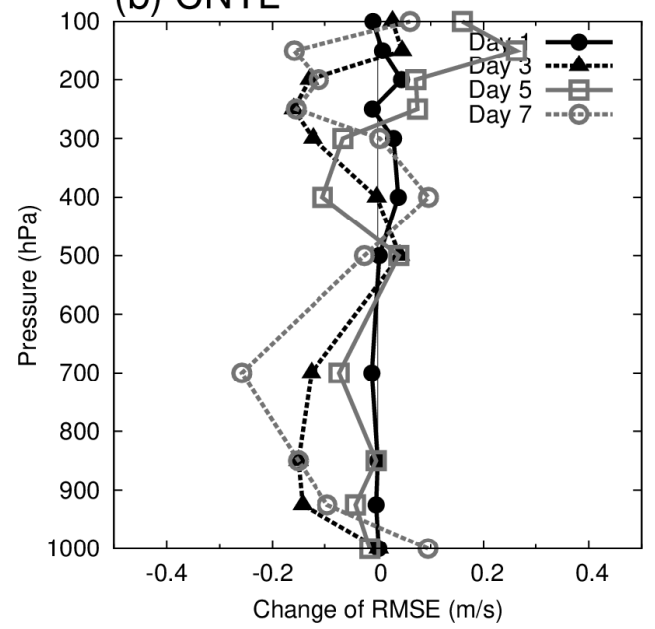

Fig. 8. Changes in RMS errors for zonal components of wind forecasts against radiosonde observations in and around Japan. (a) TEST (Himawari-8), (b) CNTL (MTSAT-2). The changes are from BASE. The X-axis shows change of RMSE expressed in $\mathrm{m} / \mathrm{s}$ while the Y-axis shows pressure expressed in $\mathrm{hPa}$. The period is from May 26 to September 30, 2015. The different line types indicate different forecast ranges (from Day 1 to Day 7) as shown in the legend.

and the surrounding areas. In TEST, a tropospheric wind field improvement of approximately $0.25 \%$ was seen in medium-range forecasts (days 5 and 7), while impacts in CNTL were mainly neutral.

CSR data are sensitive to atmospheric humidity. Wind information can be extracted from the movement of atmospheric constituents including humidity in a procedure often referred to as 'tracing'. In 4D-Var DA systems, the tracing is performed using an adjoint of forecast model equations describing the constituent transport. The 4D-Var systems can extract dynamical information from humidity-sensitive radiance data via a tracer advection mechanism (Peubey and McNally 2009). The assimilation of Himawari- 8 CSR data into the 4D-Var system therefore helped to improve wind fields in analysis and forecasts (Fig. 8).

Because the impacts from Himawari-8 CSR DA were observed for the western Pacific region (i.e., Himawari-8 observation areas), as shown in Fig. 5, the changes in weather forecasting performance can be expected there. Figure 9 presents typical examples of different forecasts for low-pressure systems between TEST and CNTL. In the latter, several excessively developed low-pressure systems around Japan were predicted. In the former, these excessive developments were suppressed and errors in forecast sea level pressure were reduced around the low-pressure systems. However, there was little impact on forecast errors associated with developed TC, as indicated in Fig. 9. This is attributable to thick cloud cover in the area, meaning that insufficient Himawari-8 CSR data were available in tropical cyclone periods and areas to reduce errors through DA.

\subsection{Impact study with JMA's mesoscale NWP system}

Three experiments were performed to evaluate the impacts of Himawari-8 CSR DA in the mesoscale DA system. In the control experiment (CNTL), the MTSAT-2 CSR data were assimilated as in the JMA operational configuration on 2015. In the test experiment (TEST), the Himawari-8 CSR data were used in place of MTSAT-2 CSR data. An experiment without Himawari-8 CSR or MTSAT-2 CSR as a BASE was also performed. Other variables (i.e., the use of the conventional/other satellite data and forecast model) were identical. The use of CSR data was the only difference among the three experiments, whose configuration is detailed in Table 3.

In the mesoscale DA experiment, the assigned observation error of Himawari-8 CSR $(1.5 \mathrm{~K})$ was increased to three times that of MTSAT-2 CSR $(1.5 \mathrm{~K})$. As the contribution of Himawari-8 CSR data in the 4D-Var cost function was much greater than that of MTSAT-2 CSR data, the related total increment after minimization was dominated by Himawari- 8 CSR data while the contributions from other observations were 

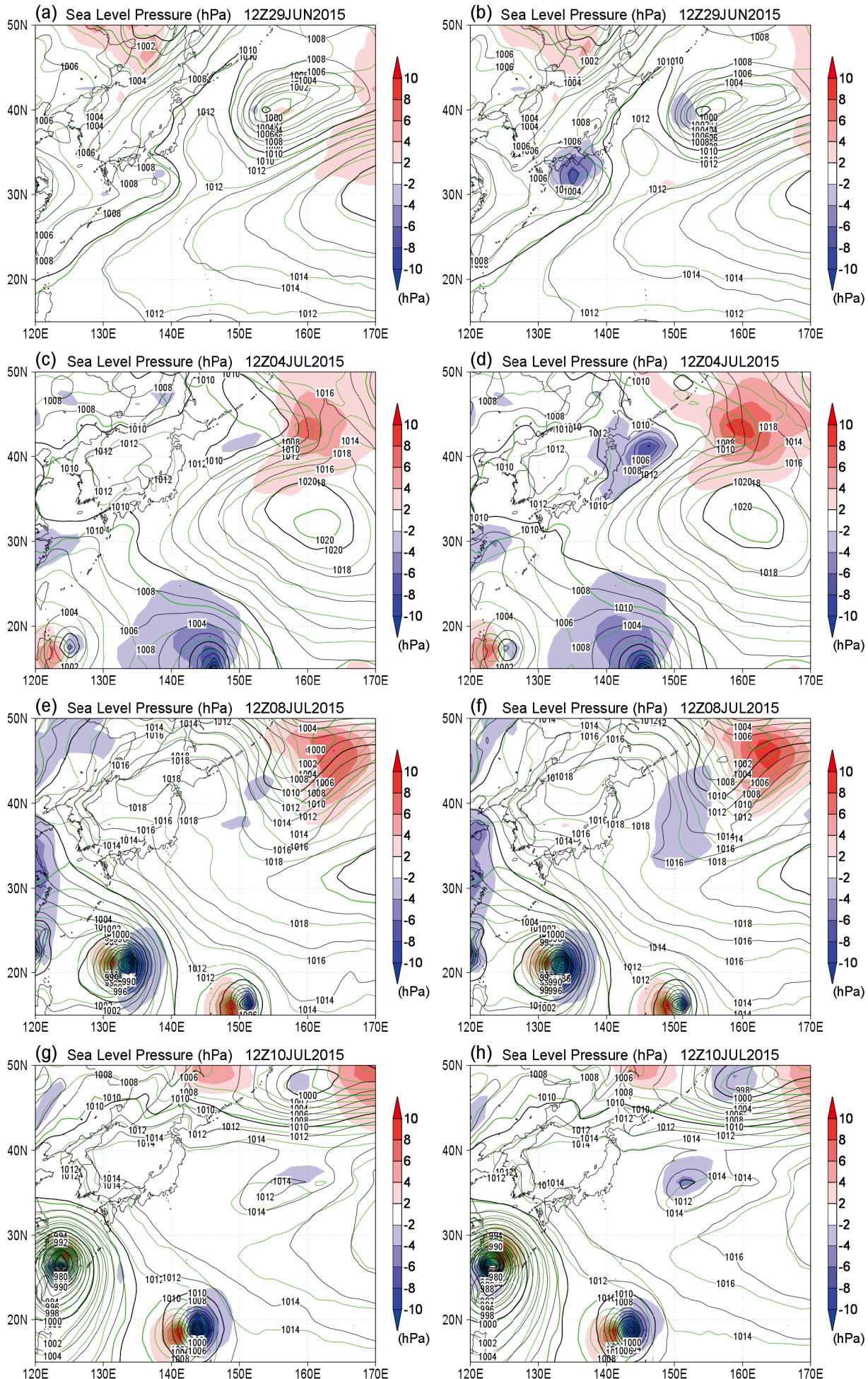

Fig. 9. Comparison of the three-day forecasts for sea-level pressure from TEST and CNTL. (a) TEST, (b) CNTL for 12 UTC June 29, 2015, (c) and (d) the same for 12 UTC July 4, 2015, (e) and (f) the same for 12 UTC July 8, 2015, and (g) and (h) the same for 12 UTC July 10, 2015. Green lines denote analysis and black lines denote forecasts. Shading indicates differences between forecasting and analysis. The units are $\mathrm{hPa}$. 
Table 3. Used CSR data in the data assimilation experiment with the mesoscale system.

\begin{tabular}{cc}
\hline Experiment Name & Used CSR data \\
\hline TEST & Himawari-8 CSR (Band 8) \\
CNTL & MTSAT-2 CSR (IR3) \\
BASE & No CSR data use \\
\hline
\end{tabular}

minor within a limited iteration time in the operational configuration. JMA's operational configuration is limited to 35 iterations, and this limit was applied to all experiments in the study. Without the inflation factor, the contribution to the cost function from Himawari-8 CSR data is nine to ten times greater than that of MTSAT-2 CSR data. In minimization, the Himawari-8 cost function was preferentially reduced at the beginning of the iteration when no inflation was applied to the observation error. This caused a worse fitting of the analysis to other observations (i.e., radiosonde temperature observation, aircraft data, and microwave imager radiance data). The above inflation factor was introduced in practice to prevent excessive fitting to Himawari-8 CSR data in minimization. The effect on the speed of cost function convergence is indicated in Fig. 10.

The experiment period was from August 2 to September 9, 2015. This period includes a heavy precipitation event that took place in the Kanto and Tohoku regions of Japan. A major difference from the (a) TEST with inflation

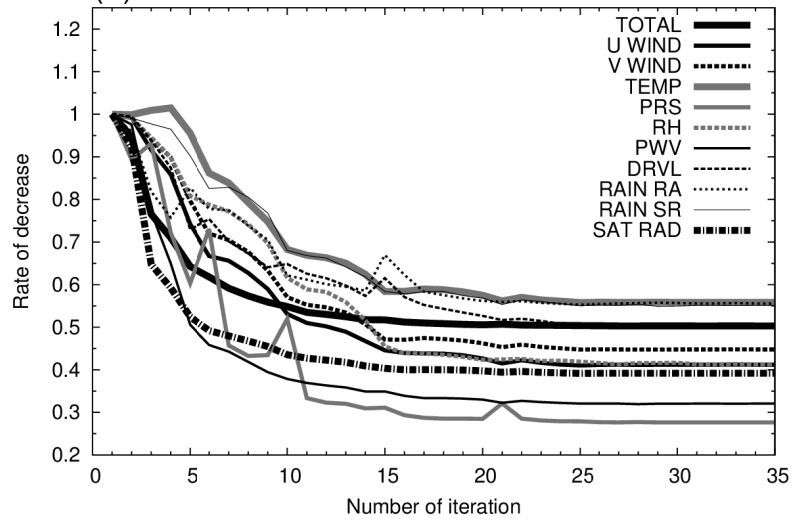

(c) CNTL

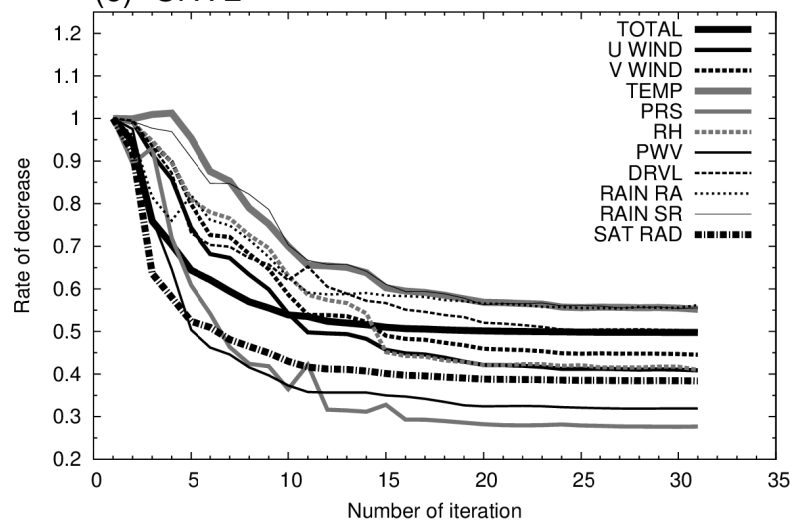

(b) TEST without inflation

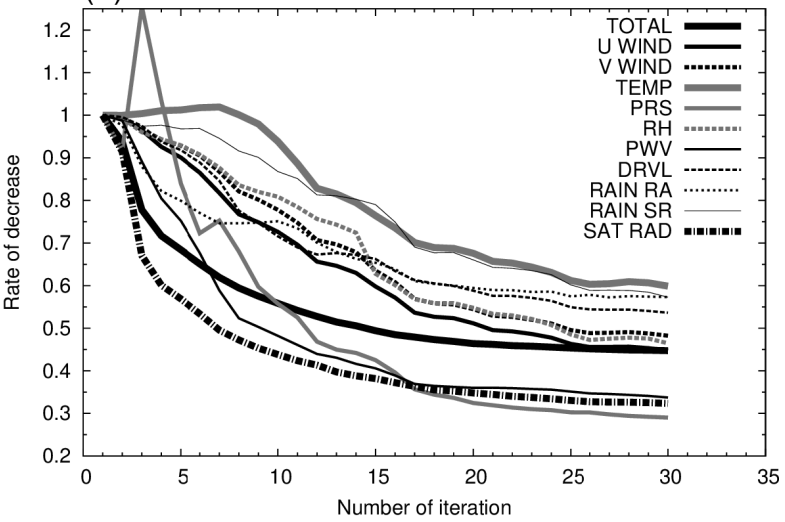

(d) BASE

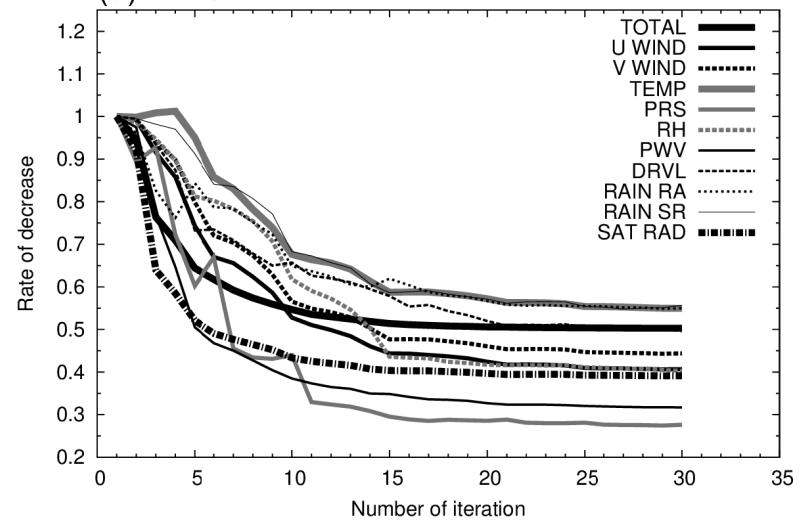

Fig. 10. Comparison of convergence in 4D-Var cost function during minimization in the mesoscale DA system for different observation types. Values are normalized at the beginning of minimization. Abbreviations denote the type of observation as follows. TOTAL - total cost, U WIND, and V WIND - individual wind components, TEMP temperature, PRS - surface pressure, PWV - precipitable water vapor, DRVL - Doppler wind velocity, RAIN_RA rain rate as determined from ground-based radars, RAIN_SA - rain rate as determined from microwave imagers, SAT_RAD - satellite radiance. (a) TEST with the inflation factor of the observation error in Himawari-8 CSR data, (b) TEST without the inflation factor, (c) CNTL, (d) BASE at 00 UTC on August 2, 2015. 
Himawari-8 CSR data usage in JMA's global NWP system is the data thinning distance. In the mesoscale NWP system, the Himawari-8 CSR data are thinned to one data point per $45 \mathrm{~km}$ grid box, as with MTSAT-2 CSR data. Figure 11 illustrates a comparison of quality-controlled Himawari-8 CSR and MTSAT-2 CSR data distribution in 12 UTC September 7, 2015 analysis and the surface weather chart for the Japan area at 00 UTC on September 7, 2015 from JMA. The increased horizontal resolution and enhanced cloud identification of Himawari-8 CSR data generally led to increased availability of CSR data in analysis. This increase for mainland China was remarkable in the MSM domain. As shown in the surface weather chart in Fig. 11, the high-pressure systems were

(a) Himawari-8 CSR

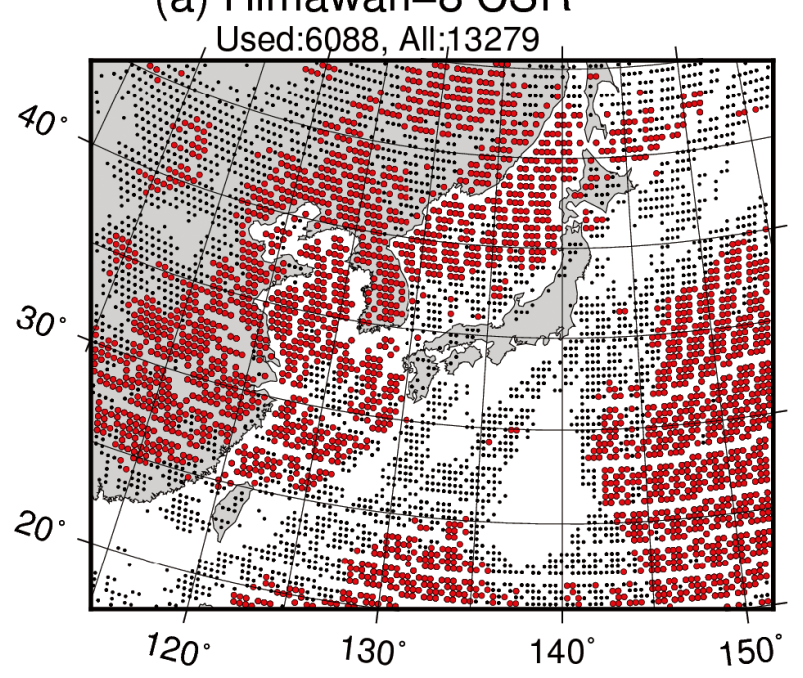

(c) Surface Weather Chart

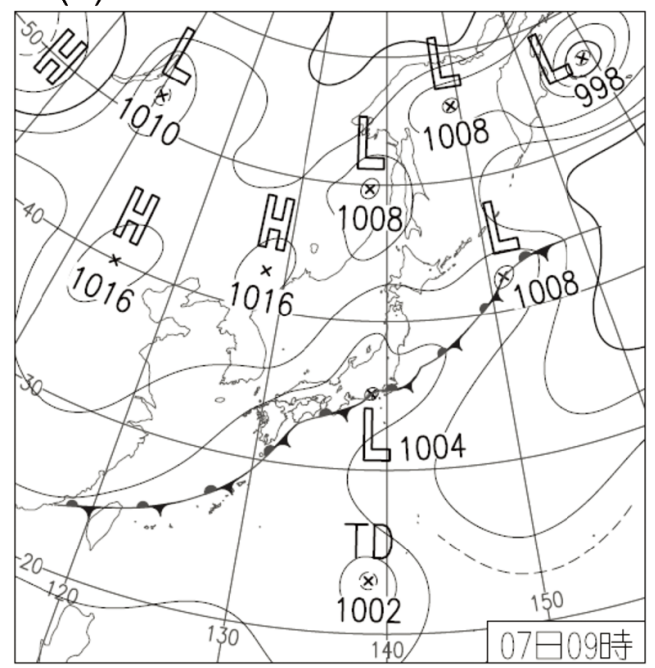

located over the continent of China, bringing clearsky conditions. Meanwhile, between the high-pressure system over the Pacific Ocean and the continental high-pressure system, a stationary front was located along the southern coast of Japan's main island and a tropical depression was approaching the front from the southern ocean of Japan. The impact of water vapor brought by this depression will be discussed later.

To evaluate the impacts on the FG field in the mesoscale system, the FG departures of MHS were examined. Comparable reductions of RMS errors in the FG departure were found in the MSM domain, as well as those from the experiments with the global NWP system. The positive impacts were statistically significant (not shown). To determine the impacts on

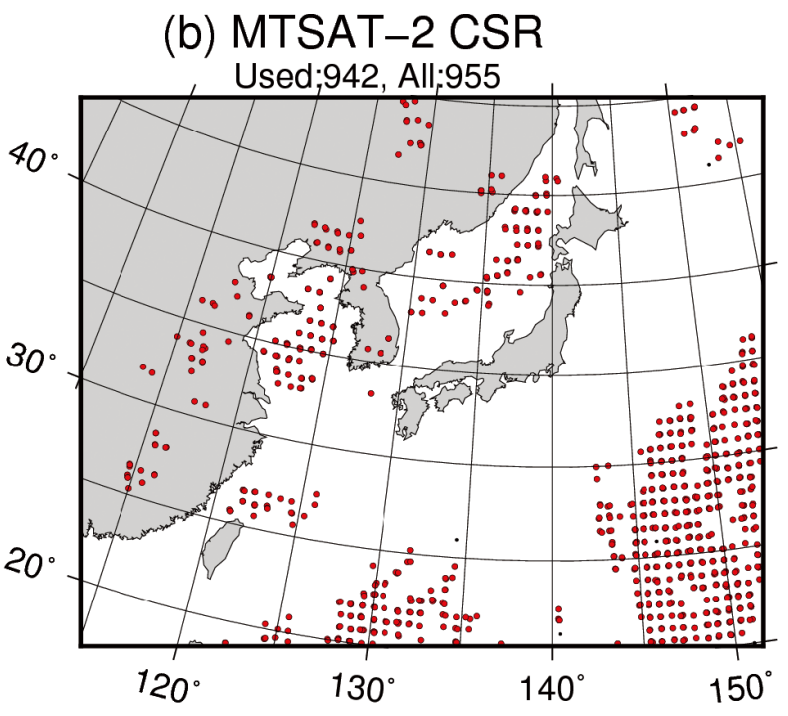

Fig. 11. CSR data coverage in the mesoscale DA system. Data are for 12 UTC September 7, 2015 analysis. (a) Himawari-8 CSR, (b) MTSAT-2 CSR. The assimilated data are shown with red dots while the data screened out in pre-processing are denoted by black dots. (c) JMA surface weather chart for 12 UTC on September 7 , 2015. 

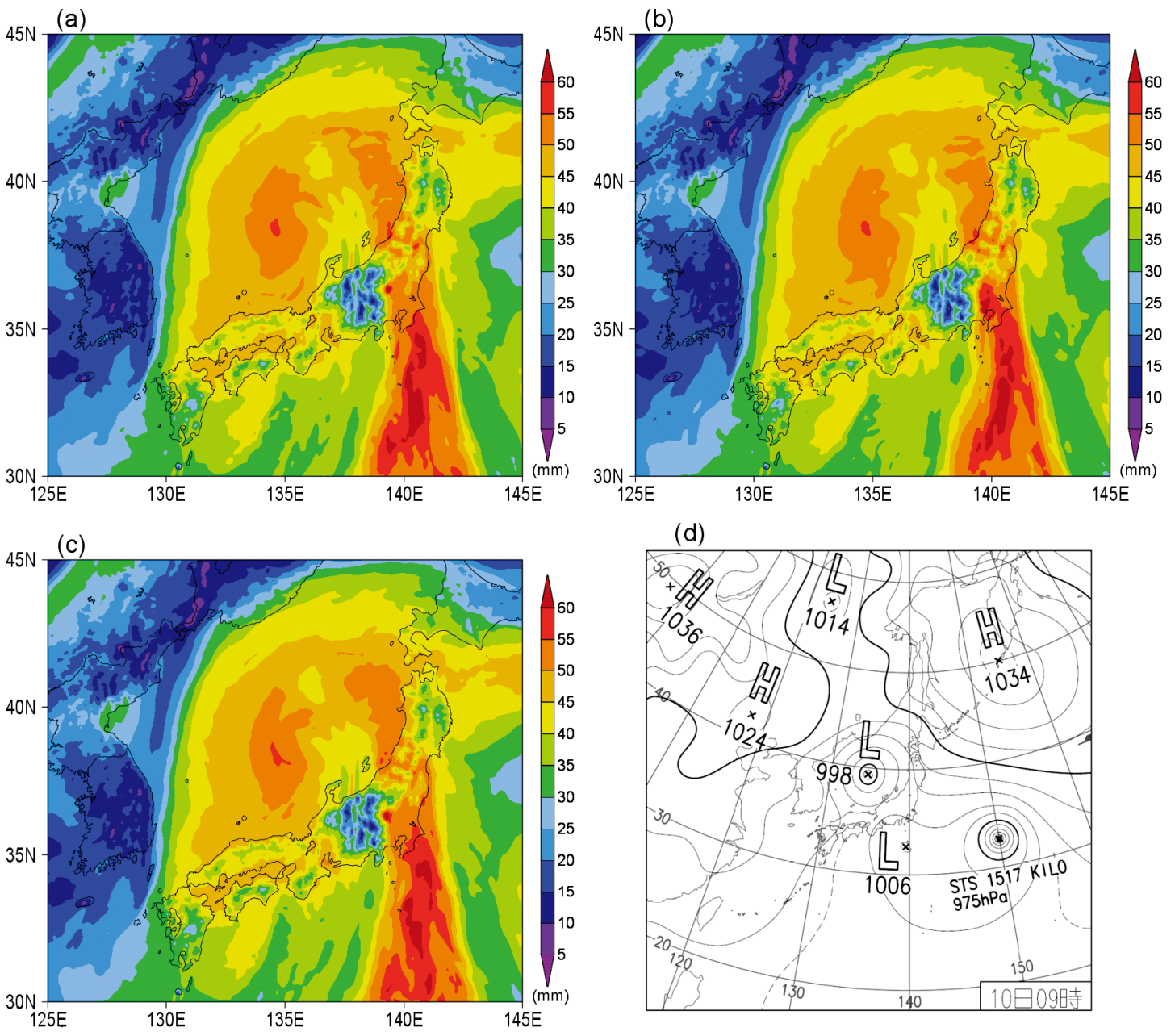

(d)
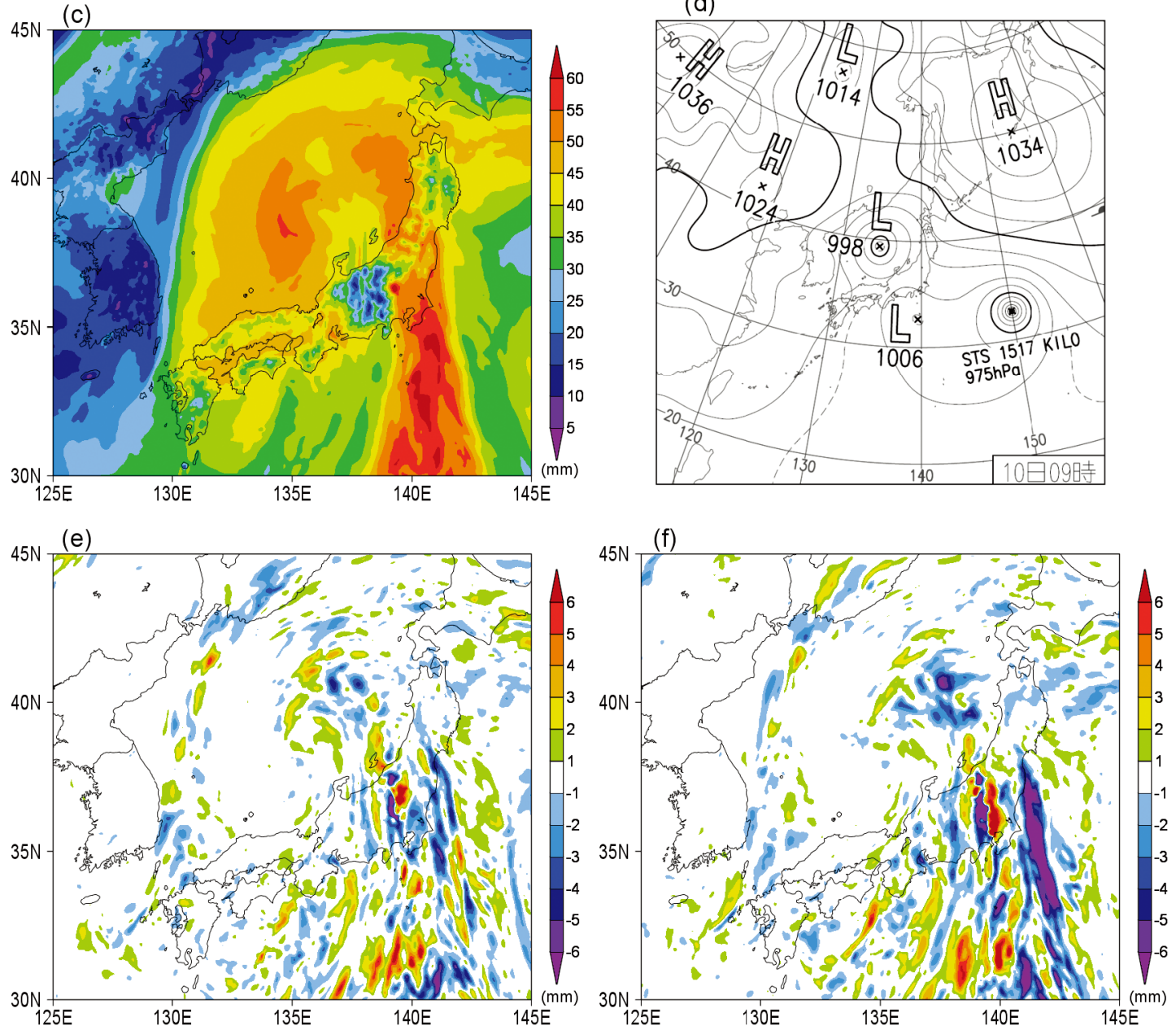

Fig. 12. Comparison of total precipitable water vapor analysis among (a) CNTL (MTSAT-2 CSR usage), (b) TEST (Himawari-8 CSR usage), and (c) BASE (no CSR usage). The analysis time is 12 UTC on September 9, 2015. (d) Surface weather chart for 00 UTC on September 10, 2015. Comparison of differences in total precipitable water vapor fields from BASE (e) CNTL-BASE and (f) TEST-BASE. The unit of total precipitable water vapor is $\mathrm{mm}$. 
forecasts of severe precipitation, the focus was placed on a heavy rainfall event that began in Japan's KantoTohoku region on September 9, 2015. Figure 12 displays a comparison of the total precipitable water vapor field in mesoscale analysis for this event. Moist air flow from the southern ocean toward the Kanto-Tohoku region was clearly represented in the analysis for data from 12 UTC on September 9. Due to the high availability of in-situ and ground-based observation data, as well as information from polarorbiting satellite data, the moist air flow was properly represented in the analysis even in the BASE (no CSR data) scenario. The characteristics of the water

(a)

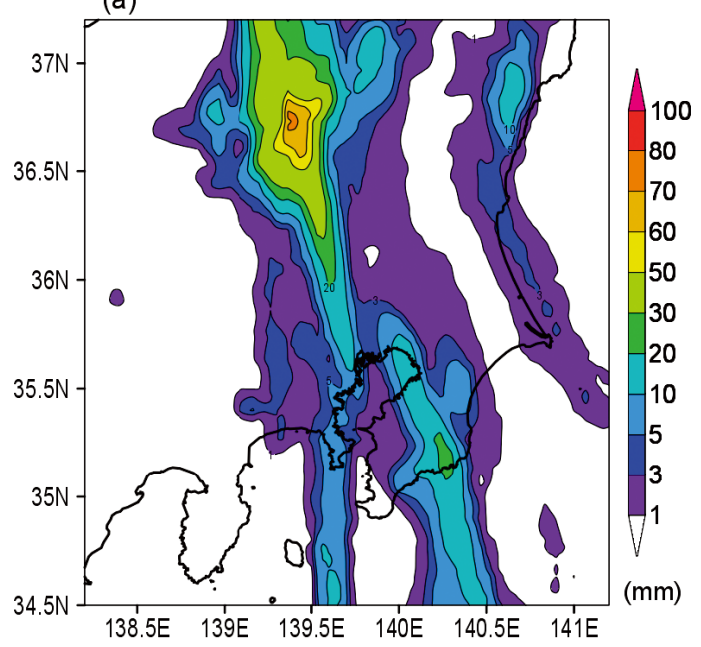

(c)

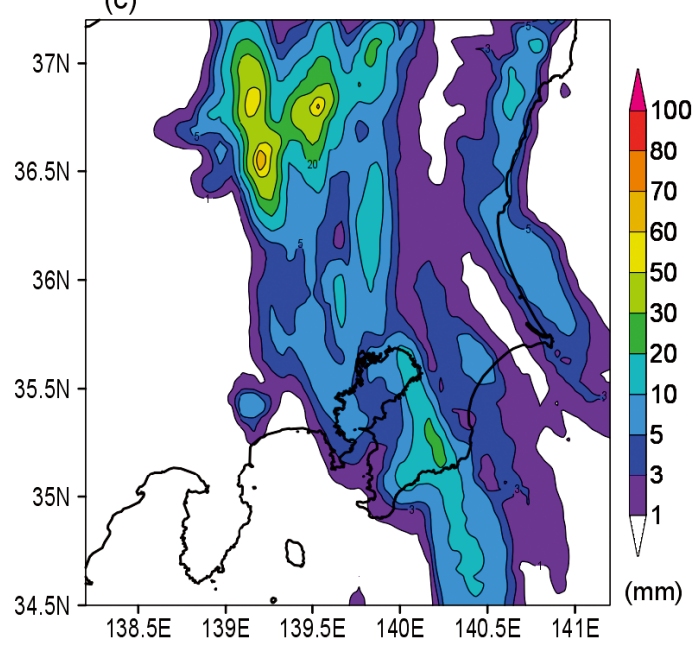

vapor field around the core of a low-pressure system over the Sea of Japan were also similar among the experiments. This area was covered with thick clouds and no CSR data were available. As a result, the CSR DA did not produce any significant difference for the area in the analysis. Meanwhile, high precipitable water vapor values (i.e., exceeding $55 \mathrm{~mm}$ ) were represented in over land analysis for the Kanto area in TEST. Differences in the precipitable water vapor field from BASE are also presented in Fig. 12. The contrast of the water vapor field along the moist air flow was remarkable in TEST.

Figure 13 displays three-hour precipitation forecasts

(b)

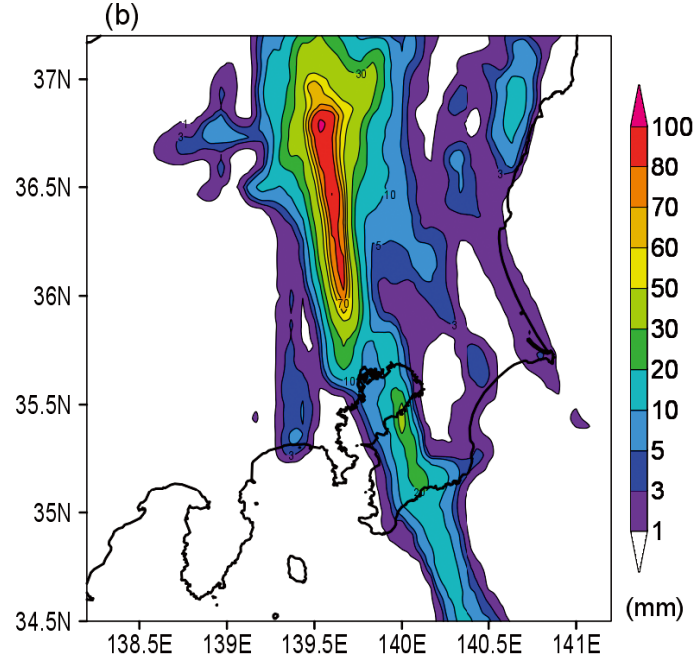

(d)

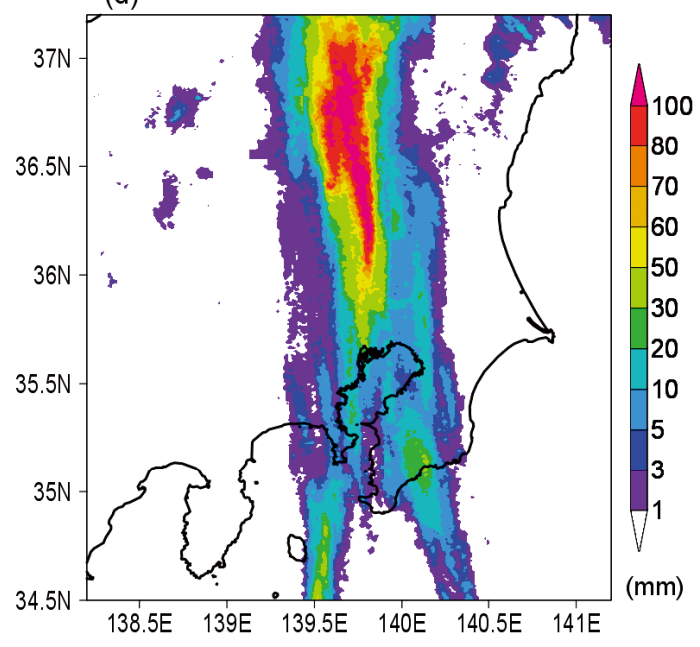

Fig. 13. Comparison of three-hour cumulative rainfall forecasts for 15 UTC on September 9, 2015. The forecast period is three hours. (a) CNTL (with MTSAT-2 CSR), (b) TEST (with Himawari-8 CSR), (c) BASE (no CSR), and (d) observed rainfall distribution from ground-based radar observations and rain-gauge data. The unit of rainfall is $\mathrm{mm}(3 \mathrm{hr})^{-1}$. 
from the initial field (12 UTC, September 9, 2015). The forecast precipitation in the TEST case was much closer to the observed precipitation than those of the other two cases, and the CNTL result showed some improvement from that of BASE. The use of CSR data generally increased the concentration of precipitation. Although both Himawari-8 CSR and MTSAT-2 CSR enhanced precipitation forecasting, the amelioration from the former was much greater.

\section{Summary and future prospects}

In this study, the impacts of Himawari-8 CSR DA in JMA's global and mesoscale NWP systems were investigated, and the related impacts of Himawari-8 CSR and MTSAT-2 CSR data were compared in a BASE. Himawari-8 CSR provide temporal, spectral, and horizontal resolutions superior to those of MTSAT-2 CSR data, and they are expected to produce greater impacts on analysis and forecasting.

In DA experiments involving the global NWP system, the assimilation of data from three Himawari- 8 water vapor bands brought greater improvement in tropospheric humidity fields than data from a single MTSAT-2 water vapor channel. FG departure statistics for MHS indicated the amelioration of the water vapor field in the lower troposphere while the impacts were particularly distinct over Himawari-8 observation areas. Enhanced forecasting was also found in terms of temperature and humidity for Himawari- 8 observation areas. Verification with RAOB wind data showed clear forecast improvements while the impacts on forecasting were lower outside Himawari-8 observation areas. This was consistent with changes in the analysis and FG field. Typical enhancements for the western Pacific region included the suppression of spuriously developed low-pressure areas in the global NWP system. It is considered that the improvements in the water vapor analysis field and FG field from Himawari-8 CSR DA have produced realistic water vapor characteristics, leading to accurate atmospheric stability under clear-sky conditions. These impacts contributed to improved prediction of low-pressure systems.

In the experiments involving the mesoscale NWP system, a disastrous heavy precipitation event that occurred in Japan was investigated. Himawari-8 CSR DA highlighted the flow of heavy water vapor from the southern ocean in the analysis. This flow was enhanced, and the representation of the surrounding precipitable water vapor field was rendered more realistic as a result of Himawari-8 CSR DA, which also led to improved heavy precipitation forecasting.
Although MTSAT-2 CSR DA produced a similar improvement, the impacts were greater with Himawari-8 CSR usage.

The horizontal resolution of Himawari-8 CSR data (i.e., $32 \mathrm{~km}$ ) may not be appropriate for use in the mesoscale DA system, whose inner-model resolution is higher at $15 \mathrm{~km}$. Future work will involve research on the use of original pixel-based Himawari-8 radiance data in the mesoscale DA system and a related impact study.

The results of CSR data assimilation experiments generally demonstrated clear benefits from the use of the Himawari-8 CSR data in JMA's global and mesoscale DA systems. Such utilization improved the tropospheric water vapor analysis and weather/ precipitation forecasting in JMA's NWP systems. The enhanced specifications (i.e., temporal, horizontal, and spectral resolutions) of Himawari-8 AHI data were exploited to a certain extent in CSR DA experiments.

GOES-16 geostationary satellite has now been launched. GOES-16 carries the Advanced Baseline Imager (ABI). ABI observes the Earth with 16 different spectral bands, including two visible channels, four near-infrared channels, and ten infrared channels. The instrument design is similar to that of Himawari-8 AHI. The geostationary satellites of Meteosat third generation are set to be launched in the near future. They will carry a hyper-spectral infrared sounder instrument. These new instruments provide large observational information for operational data assimilation and prediction. Development of all-sky infrared radiance assimilation is also in progress at a variety of NWP centers (Lupu and McNally 2012; Okamoto 2013; Geer et al. 2018; Okamoto 2017). Against such a background, the assimilation of geostationary satellite radiance data for all-sky conditions is expected to bring remarkable progress in NWP accuracy over the next decade.

\section{Acknowledgments}

The author is grateful to the staff of JMA's Numerical Prediction Division who provided helpful input and insightful comments during the compilation of this manuscript. Thanks are also due to Daisaku Uesawa and Takahito Imai of JMA's Meteorological Satellite Center for providing Himawari-8 CSR data and for their useful advice and comments on data quality. The author also acknowledges the two anonymous reviewers who provided valuable comments and suggestions on the paper. 


\section{References}

Bauer, P., P. Lopez, A. Benedetti, D. Salmond, and E. Moreau, 2006: Implementation of 1D+4D-Var assimilation of precipitation-affected microwave radiances at ECMWF. I: 1D-Var. Quart. J. Roy. Meteor. Soc., 132, 2277-2306.

Bessho, K., K. Date, M. Hayashi, A. Ikeda, T. Imai, H. Inoue, Y. Kumagai, T. Miyakawa, H. Murata, T. Ohno, A. Okuyama, R. Oyama, Y Sasaki, Y. Shimazu, K. Shimoji, Y. Sumida, M. Suzuki, H. Taniguchi, H. Tsuchiyama, D. Uesawa, H. Yokota, and R. Yoshida, 2016: An introduction to Himawari-8/9 _ Japan's newgeneration geostationary meteorological satellites. $J$. Meteor. Soc. Japan, 94, 151-183.

Courtier, P., J.-N. Thépaut, and A. Hollingsworth, 1994: A strategy for operational implementation of 4D-Var, using an incremental approach. Quart. J. Roy. Meteor. Soc., 120, 1367-1387.

Dee, D. P., 2004: Variational bias correction of radiance data in the ECMWF system. Proceedings of the ECMWF NASA GMAO Workshop on Assimilation of High Spectral Resolution Sounders in NWP, ECMWF, Reading, UK, 97-112.

Geer, A. J., K. Lonitz, P. Weston, M. Kazumori, K. Okamoto, Y. Zhu, E. H. Liu, A. Collard, W. Bell, S. Migliorini, P. Chambon, N. Fourrié, M.-J. Kim, C. Köpken-Watts, and C. Schraff, 2018: All-sky satellite data assimilation at operational weather forecasting centres. Quart. J. Roy. Meteor. Soc., 144, 1191-1217.

Honda, Y., M. Nishijima, K. Koizumi, Y. Ohta, K. Tamiya, T. Kawabata, and T. Tsuyuki, 2005: A pre-operational variational data assimilation system for a nonhydrostatic model at the Japan Meteorological Agency: Formulation and preliminary results. Quart. J. Roy. Meteor. Soc., 131, 3465-3475.

Ikuta, Y., 2016: Data assimilation using GPM/DPR at JMA. WGNE Blue Book, Res. Activ. Atmos. Oceanic Modell., 46, 1-11.

Ikuta, Y., and Y. Honda, 2011: Development of 1D+4DVAR data assimilation of radar reflectivity in JNoVA. WGNE Blue Book, Res. Activ. Atmos. Oceanic Modell., 41, 1-09.

Imai, T., and D. Uesawa, 2016: Clear Sky Radiance (CSR) product derived from Himawari-8 data. Meteorol. Satell. Cent. Tech. Note, 61, 53-58.

Ishibashi, T., 2008: Assimilation of WV CSR from MTSAT$1 \mathrm{R}$ in the JMA global 4DVAR system. WGNE Blue Book, Res. Activ. Atmos. Oceanic Modell., 38, 1-09.

Japan Meteorological Agency, 2013: Outline of the operational numerical weather prediction at the Japan Meteorological Agency. Appendix to WMO Technical Progress Report on The Global Data Processing and Forecasting SYSTEM (GDPFS) and Numerical Weather Prediction (NWP) Research, Japan Meteorological Agency, Tokyo, Japan, 187 pp.
Kazumori, M., 2014: Satellite radiance assimilation in the JMA operational mesoscale 4DVAR system. Mon. Wea. Rev., 142, 1361-1381.

Kazumori, M., 2016: Assimilation of GPM microwave imager data in JMA's NWP systems. WGNE Blue Book, Res. Activ. Atmos. Oceanic Modell., 46, 1-13.

Kazumori, M., and T. Egawa, 2014: Assimilation of GCOMW1/AMSR2 radiance data into JMA's NWP systems. WGNE Blue Book, Res. Activ. Atmos. Oceanic Modell., 44, 1-07.

Koizumi, K., Y. Ishikawa, and T. Tsuyuki, 2005: Assimilation of precipitation data to the JMA mesoscale model with a four-dimensional variational method and its impact on precipitation forecasts. SOLA, 1, 45-48.

Köpken, C., G. Kelly, and J.-N. Thépaut, 2004: Assimilation of Meteosat radiance data within the 4D-Var system at ECMWF: Assimilation experiments and forecast impact. Quart. J. Roy. Meteor. Soc., 130, 2277-2292.

Lawrence, H., J. Letertre-Danczak, K. Lean, K. Salonen, and N. Bormann, 2016: New satellite data reduce forecast errors. ECMWF Newsletter, 148, 8-9.

Lupu, C., and A. P. McNally, 2011: Assimilation of radiance products from geostationary satellites: 1-year report. EUMETSAT/ECMWF Fellowship Programme Research Report, 21, 27 pp.

Lupu, C., and A. P. McNally, 2012: Assimilation of cloudaffected radiances from Meteosat-9 at ECMWF. EUMETSAT/ECMWF Fellowship Programme Research Report, 25, 33 pp.

Ma, Z., E. S. Maddy, B. Zhang, T. Zhu, and S. A. Boukabara, 2017: Impact assessment of Himawari-8 AHI data assimilation in NCEP GDAS/GFS with GSI. $J$. Atmos. Oceanic Technol., 34, 797-815.

Météo-France, 2016: The Météo-France operational NWP system: Description and recent changes (May 2016). 24 pp. [Available at https://www.umr-cnrm.fr/IMG/ pdf/nwpreport_2016.pdf.]

Met Office, 2016: The latest Met Office Global model improvements. Research news. [Available at https:// www.metoffice.gov.uk/research/news/2016/latest-metoffice-global-model-improvements.]

Munro, R., C. Köpken, G. Kelly, J.-N. Thépaut, and R. Saunders, 2004: Assimilation of Meteosat radiance data within the 4D-Var system at ECMWF: Data quality monitoring, bias correction and single-cycle experiments. Quart. J. Roy. Meteor. Soc., 130, 2293-2313.

Okamoto, K., 2013: Assimilation of overcast cloudy infrared radiances of the geostationary MTSAT-1R imager. Quart. J. Roy. Meteor. Soc., 139, 715-730.

Okamoto, K., 2017: Evaluation of IR radiance simulation for all-sky assimilation of Himawari-8/AHI in a mesoscale NWP system. Quart. J. Roy. Meteor. Soc., 143, 1517-1527.

Peubey, C., and A. P. McNally, 2009: Characterization of the 
impact of geostationary clear-sky radiances on wind analyses in a 4D-Var context. Quart. J. Roy. Meteor. Soc., 135, 1863-1876.

Qin, Z., X. Zou, and F. Weng, 2013: Evaluating added benefits of assimilating GOES imager radiance data in GSI for coastal QPFs. Mon. Wea. Rev., 141, 75-92.

Saito, K., T. Fujita, Y. Yamada, J. Ishida, Y. Kumagai, K. Aranami, S. Ohmori, R. Nagasawa, S. Kumagai, C. Muroi, T. Kato, H. Eito, and Y. Yamazaki, 2006: The operational JMA nonhydrostatic mesoscale model. Mon. Wea. Rev., 134, 1266-1298.

Sato, Y., 2007: Introduction of variational bias correction technique into JMA global data assimilation system. WGNE Blue Book, Res. Activ. Atmos. Oceanic Modell., 37, 1-19.

Sato, Y., Y. Takeuchi, and T. Tauchi, 2004: Use of TMI and $\mathrm{SSM} / \mathrm{I}$ data in the JMA operational meso analysis. WGNE Blue Book, Res. Activ. Atmos. Oceanic Modell., 34, 1-27.

Saunders, R., M. Matricardi, and P. Brunel, 1999: An improved fast radiative transfer model for assimilation of satellite radiance observations. Quart. J. Roy. Meteor. Soc., 125, 1407-1425.

Saunders, R., J. Hocking, P. Rayer, M. Matricardi, A. Geer, N. Bormann, P. Brunel, F. Karbou, and F. Aires, 2012: RTTOV-10 science and validation report. NWPSAFMO-TV-023, v1.11, EUMETSAT NWP-SAF, 28 pp.

Smith, W. L., D. K. Zhou, H.-L. Huang, J. Li, X. Liu, and A. M. Larar, 2004: Extraction of profile information from cloud contaminated radiances. Proc. ECMWF Workshop on Assimilation of High Spectral Resolution Sounder in NWP, 145-154.

Stengel, M., P. Undén, M. Lindskog, P. Dahlgren, N. Gustafsson, and R. Bennartz, 2009: Assimilation of SEVIRI infrared radiances with HIRLAM 4D-Var. Quart. J. Roy. Meteor. Soc., 135, 2100-2109.

$\mathrm{Su}$, X., J. Derber, J. Jung, Y. Tahara, D. Keyser, and R. Treadon, 2003: The usage of GOES imager clear- sky radiance in the NCEP Global Data Assimilation System. Preprints, 12th Conf. on Satellite Meteorological and Oceanography. Long Beach, CA, Amer. Meteor. Soc., P3. 20.

Szyndel, M. D. E., G. Kelly, and J. N. Thépaut, 2005: Evaluation of potential benefit of assimilation of SEVIRI water vapour radiance data from Meteosat-8 into global numerical weather prediction analyses. Atmos. Sci. Lett., 6, 105-111.

Tingwell, C., F. Baordo, I. Dharssi, P. Gregory, Vinodkumar, J. Lee, J. Le Marchall, K. Puri, P. Steinle, and Y. Xiao, 2015: Recent upgrades to the Bureau of Meteorology ACCESS NWP system. Proceeding of the 20th International TOVS Study Conference, Lake Geneva, Wisconsin, USA.

Uesawa, D., 2009: Clear Sky Radiance (CSR) product from $M T S A T-1 R$. Meteorological Satellite Center Technical Note, 52, 39-48.

Verner, G., and G. Deblonde, 2012: Status of operational satellite data assimilation at environment Canada. Proceeding of 18th International TOVS Study Conference, Toulouse, France, 21-27 March 2012. [Available at https://cimss.ssec.wisc.edu/itwg/itsc/itsc18/ program/files/links/4.03_Verner_po.pdf.]

Wang, P., J. Li, M. D. Goldberg, T. J. Schmit, A. H. N. Lim, Z. Li, H. Han, J. Li, and S. A. Ackerman, 2015: Assimilation of thermodynamic information from advanced infrared sounders under partially cloudy skies for regional NWP. J. Geophys. Res., 120, 54695484.

Zou, X., Z. Qin, and F. Weng, 2011: Improved coastal precipitation forecasts with direct assimilation of GOES-11/12 imager radiances. Mon. Wea. Rev., 139, 3711-3729.

Zou, X., Z. Qin, and Y. Zheng, 2015: Improved tropical storm forecasts with GOES-13/15 imager radiance assimilation and asymmetric vortex initialization in HWRF. Mon. Wea. Rev., 143, 2485-2505. 